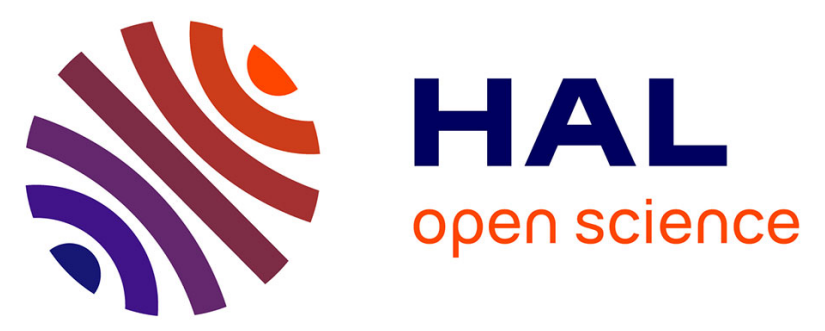

\title{
Spectral Induced Polarization Characterization of Non-Consolidated Clays for Varying Salinities-An Experimental Study
}

\author{
Aida Mendieta, Damien Jougnot, Philippe Leroy, Alexis Maineult
}

\section{To cite this version:}

Aida Mendieta, Damien Jougnot, Philippe Leroy, Alexis Maineult. Spectral Induced Polarization Characterization of Non-Consolidated Clays for Varying Salinities-An Experimental Study. Journal of Geophysical Research : Solid Earth, 2021, 126 (4), 10.1029/2020JB021125 . hal-03247021

\section{HAL Id: hal-03247021 \\ https://hal.sorbonne-universite.fr/hal-03247021}

Submitted on 2 Jun 2021

HAL is a multi-disciplinary open access archive for the deposit and dissemination of scientific research documents, whether they are published or not. The documents may come from teaching and research institutions in France or abroad, or from public or private research centers.
L'archive ouverte pluridisciplinaire HAL, est destinée au dépôt et à la diffusion de documents scientifiques de niveau recherche, publiés ou non, émanant des établissements d'enseignement et de recherche français ou étrangers, des laboratoires publics ou privés. 


\title{
Spectral induced polarization characterization of non-consolidated clays for varying salinities - an experimental study
}

\author{
Aida Mendieta ${ }^{1}$, Damien Jougnot ${ }^{1}$, Philippe Leroy ${ }^{2}$, and Alexis Maineult ${ }^{1}$ \\ ${ }^{1}$ Sorbonne Université, CNRS, EPHE, UMR 7619 METIS, 75005 Paris, France \\ ${ }^{2}$ BRGM, French Geological Survey, 45060 Orléans, France
}

Key Points:

- The quadrature conductivity of clays behaves non-monotonously with increasing salinity

- Some polarization mechanisms may cease to act or decrease significantly at a specific salinity

- The quadrature to surface conductivity ratio is lower for clays than for other minerals

Corresponding author: Aida Mendieta, aida.mendieta_tenorio@upmc.fr 


\section{Abstract}

Clay material characterization is of importance for many geo-engineering and environmental applications, and geo-electrical methods are often used to detect them in the subsurface. Spectral induced polarization (SIP) is a geo-electric method that non-intrusively measures the frequency-dependent complex electrical conductivity of a material, in the $\mathrm{mHz}$ to the $\mathrm{kHz}$ range. We present a new SIP dataset of four different types of clay (a red montmorillonite sample, a green montmorillonite sample, a kaolinite sample, and an illite sample) at five different salinities (initially de-ionized water, $10^{-3}, 10^{-2}, 10^{-1}$, and $1 \mathrm{~mol} / \mathrm{L}$ of $\mathrm{NaCl}$ ). We propose a new laboratory protocol that allows the repeatable characterization of clay samples. The complex conductivity spectra are interpreted with the widely used phenomenological double-Pelton model. We observe an increase of the real part of the conductivity with salinity for all types of clay, while the imaginary part presents a non monotonous behavior. The decrease of polarization over conduction with salinity is interpreted as evidence that conduction increases with salinity faster than polarization. We test the empirical petrophysical relationship between $\sigma_{\text {surf }}^{\prime \prime}$ and $\sigma_{\text {surf }}^{\prime}$ and validate this approach based on our experimental data and two other datasets from the literature. With this dataset we can better understand the frequency-dependent electrical response of different types of clay. This unique dataset of complex conductivity spectra for different types of clay samples is a step forward toward better characterization of clay formations in situ.

\section{Introduction}

Clay minerals are ubiquitous in the Earth's subsurface and can be found in many geological formations, from hard clay rocks to disseminated clay aggregates or lenses in other sedimentary rocks. These minerals are frequently the main components of extended sedimentary stratigraphic layers. Illite and smectite alone may constitute around 30\% of all sedimentary rocks (Garrels \& Mackenzie, 1971). Clay materials are fine-grained soil materials (particle size below $2 \mu \mathrm{m}$ ) characterized by a large fraction of nanopores, high specific surface area (between 10 and $1000 \mathrm{~m}^{2} / \mathrm{g}$ ), and a large negative surface charge (between -0.15 and -0.10 $\mathrm{Cm}^{-2}$ ) (e.g., Michot \& Villiéras, 2006), thus large cationic exchange capacity (CEC, between 0.03 and $1.5 \mathrm{meq}^{-1}$ ) and low permeability (typically below $10^{-16} \mathrm{~m}^{2}$ )(Revil \& Leroy, 2004). These properties make clay formations suitable to be, e.g.: cap rocks forming geo-reservoirs, aquitards defining the geometry of hydrosys- 
tems, or potential hosts for waste repositories. Studying the transport and mechanical properties of clay materials is crucial for many geoengineering and environmental applications, such as: oil and gas (e.g., Morsy \& Sheng, 2014), geothermal energy exploration and production (e.g., Corrado et al., 2014), critical zone research (e.g., Chorover et al., 2007), nuclear waste storage (e.g., Gonçalvès et al., 2012; Ortiz et al., 2002), hydrogeology (e.g., Parker et al., 2008; Konikow et al., 2001), civil engineering (e.g., Islam et al., 2020), among others.

Clay formations are geological formations composed of a majority of clay minerals. Clay minerals are hydrous aluminium phyllosilicates, that is, silicates organized in stacks of tetrahedral $(\mathrm{T})$ silica sheets and aluminium octahedral $(\mathrm{O})$ sheets called platelets (Bergaya \& Lagaly, 2006). The $\mathrm{T}$ and $\mathrm{O}$ sheets present an overall negative electrical charge at their surfaces because of deprotonated oxygen atoms and isomorphic substitutions in the crystal lattice (Leroy \& Revil, 2004). Due to these charges on the clay surface, cations (e.g.: $\mathrm{Ca}^{2+}, \mathrm{Na}^{+}, \mathrm{Mg}^{2+}, \mathrm{K}^{+}$) can be adsorbed in the interlayer space of illite, smectite and chlorite minerals between platelets; and on the external surface in the electrical double layer (EDL) made of the Stern and diffuse layer (Leroy \& Revil, 2009). The differences between clay minerals depend on the kind of tetrahedral and octahedral stacks (1:1 for TO or 2:1 for TOT) and adsorbed cations in the interlayer space (e.g., $\mathrm{K}^{+}$for illite or $\mathrm{Na}^{+}$and $\mathrm{Ca}^{2+}$ for montmorillonite) (Brigatti et al., 2006). The clay platelets are then organized in tactoids, that is, stacks of platelets having different geometries, which form aggregates (Bergaya \& Lagaly, 2006). There are four main groups of clay minerals: kaolinite, illite, smectite, and chlorite.

The total specific surface area of a kaolinite tactoid, typically $10-20 \mathrm{~m}^{2} / \mathrm{g}$, is considerably lower than the total specific surface area of an illite and montmorillonite tactoid (typically $100-200 \mathrm{~m}^{2} / \mathrm{g}$ for illite and $750-800 \mathrm{~m}^{2} / \mathrm{g}$ for Na-montmorillonite)(Hassan et al., 2006; Revil \& Leroy, 2004; Tournassat et al., 2011, 2015). Clay formations can be constituted of a mixture or stratifications of different clay minerals (e.g., inter-stratified illite-smectite). In the present work, we focus on the three more common groups: kaolinite $(1: 1)$, illite $(2: 1)$, and smectite $(2: 1$, montmorillonites are part of the smectite family). As presented previously, kaolinite, illite and smectite groups present many different characteristics in terms of structure (e.g., number of stacked platelets, tactoid size and shape), physicochemical properties (e.g., surface charges, CEC), mechanical properties (e.g., plasticity, resistance to stress, swelling-shrinking), and also electrical prop- 
erties. It is therefore crucial to electrically discriminate these minerals between each other in order to characterize the properties of the formation or predict its behavior if submitted to stress (e.g., hydraulic, mechanic, thermic).

In geophysics, the most common methods to identify the presence of clay minerals nonintrusively in the field are electrical and electromagnetic methods (e.g., Auken et al., 2017): direct current electrical resistivity tomography (ERT) (e.g., Batayneh, 2006), induced polarization (IP) (e.g., Okay et al., 2013; Lévy et al., 2019a), time-domain electromagnetics (TDEM) (e.g., Finco et al., 2018), frequency-domain (FDEM) electromagnetics (e.g., Spichak \& Manzella, 2009), and ground penetrating radar (GPR) (e.g., Looms et al., 2018). However, if clays are usually associated to high electrical conductivity zones, they can be mistaken with highly mineralized pore water when only the real electrical conductivity is considered. One way to avoid this misinterpretation is to use the complex conductivity (inferred from IP), that is the real and imaginary parts of the conductivity, or its spectral behavior, i.e. the dependence with frequency of the conductivity, to extract more information than from a single frequency measurement.

The spectral induced polarization (SIP) method can investigate the conduction and polarization of geological materials over a large range of frequencies: from the $\mathrm{mHz}$ to the kHz (e.g., Kemna et al., 2012; Revil et al., 2012). Indeed, in addition to the resistivity, the SIP method gives the chargeability of the investigated porous medium, which describes its capability to reversibly store electrical charges (e.g., Revil et al., 2012; Tabbagh et al., 2021). The chargeability is very sensitive to the pore structure and electrical surface properties (Leroy \& Revil, 2009). When SIP measurements are coupled with a relevant petrophysical model, they can provide information on the nature and behavior of electrical phenomena (conduction and polarization) happening at the pore scale (Revil, 2012), helping to interpret field scale geophysical electrical measurements in terms of mineralogy, pore structure, water content, and permeability distribution (Okay et al., 2013; Ghorbani et al., 2009).

The frequency-dependent electrical response of clay minerals has been recently studied in well-controlled conditions in the laboratory. Many clayey materials have been studied, from mixtures containing quartz sand and clays (e.g., Breede et al., 2012; Okay et al., 2014; Wang \& Slater, 2019), synthetic clay suspensions (e.g., Leroy et al., 2017a), to natural clays and clayrocks (e.g., Lévy et al., 2018; Jougnot et al., 2010). These mea- 
surements have been performed in saturated (e.g., Lévy et al., 2019b) or partially watersaturated (e.g., Cosenza et al., 2008; Ghorbani et al., 2009; Jougnot et al., 2010) conditions.

However, as pointed out by Leroy \& Revil (2009) and Leroy et al. (2017a), there is a lack of SIP laboratory studies on individual clay minerals. Indeed, measuring the frequencydependent electrical response of individual clay minerals is of great importance to better understand their specific conduction and polarization and to improve their geophysical imaging. This is needed in order to move towards a full discrimination of clay minerals when interpreting field electrical measurements. This can only be achieved by better understanding the electrical signal of each individual type of clay. In this paper, we intend to characterize the electrical signal of a variety of clay samples at multiple frequencies (from $\mathrm{mHz}$ to $\mathrm{kHz}$ ) and at multiple salinities (from initially de-ionized water to $1 \mathrm{~mol} / \mathrm{L}$ of $\mathrm{NaCl}$ ) using laboratory SIP measurements on three groups of clay minerals: illite, smectite, and kaolinite.

In the present contribution, we first present the method and some theoretical background for the SIP of clay materials. Then, we detail the protocol we propose in order to obtain the clay samples, characterize them, perform the SIP measurements, and post-treat them. We present the results on four clay samples (two smectite samples, a kaolinite sample, and an illite sample) at five different salinities (initially de-ionized water, $10^{-3}, 10^{-2}, 10^{-1}$, and $1 \mathrm{~mol} / \mathrm{L}$ of $\mathrm{NaCl}$ ) and analyze them using a phenomenological model. Finally, we discuss our results with respect to the existing literature.

\section{Theory}

\subsection{Characteristics of kaolinite, illite, and montmorillonite}

As mentioned earlier, clay minerals have a strong electrical conductivity response due to the high surface conductivity associated with the high electrical charge on their surface (Revil \& Leroy, 2004; Revil, 2012). This particularity, in addition to the heterogeneities of the surface electrical properties of clay minerals (Leroy \& Revil, 2004), makes clay systems quite complex but also, interesting to characterize electrically.

Kaolinite is a 1:1 clay, composed of a succession of silica tetrahedral (T) and aluminum octahedral $(\mathrm{O})$ sheets (see Figure 1a) whereas illite and montmorillonite (member of the smectite group) are 2:1 clays made up of a succession of TOT sheets (see Figure 1b) (Leroy 
a) Kaolinite
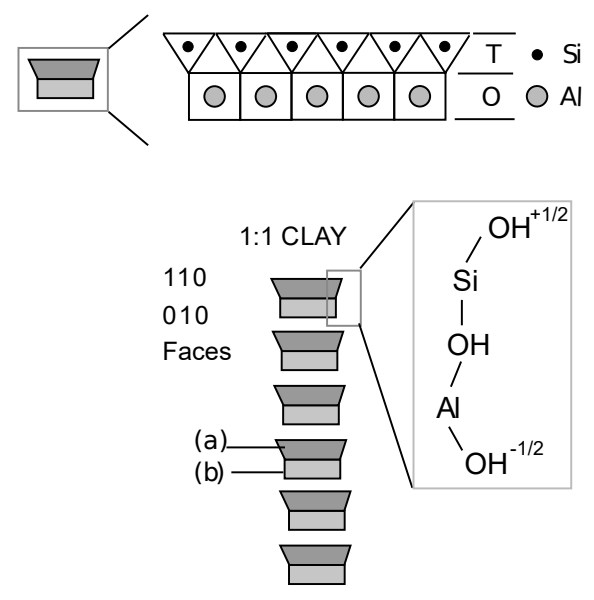

(a) Tetrahedral sheet $(\mathrm{T})$

(b) Octahedral sheet $(\mathrm{O})$

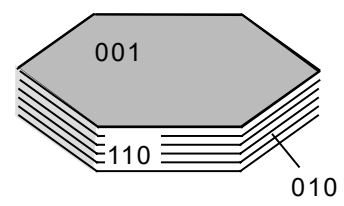

b) Illite and montmorillonite

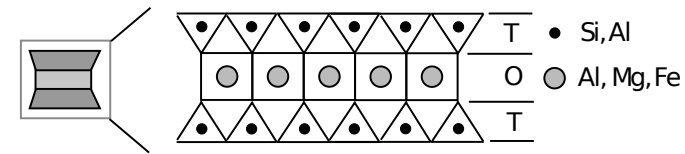

Edge: salinity and $\mathrm{pH}$-dependent surface charge

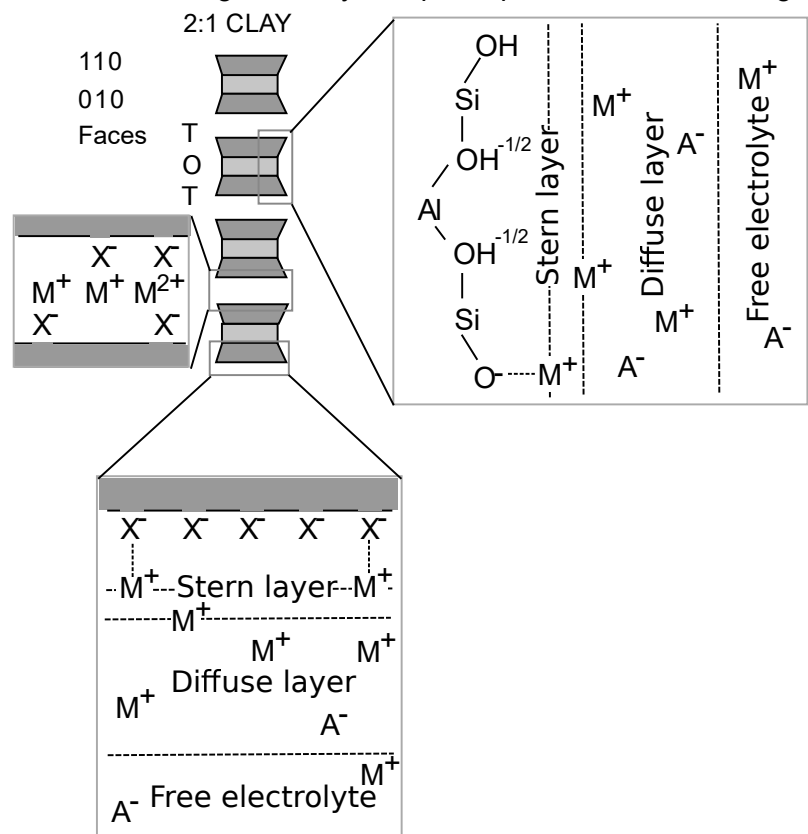

Basal: permanent negative surface charge

Figure 1. Sketch of a (a) kaolinite and an (b) illite or montmorillonite clay tactoid showing the different types of surface sites on the basal and edge surfaces as well as the electrical double layer around them (electrical double layer not shown for kaolinite) and the interlayer space between TOT sheets (modified from Leroy \& Revil, 2009). 
\& Revil, 2009). The thickness of a TOT platelet is around $9.5 \AA$, its length is around 50-100 nm for illite and 50-1000 nm for montmorillonite (Tournassat et al., 2015). For kaolinite, the thickness of a TO platelet is around $7 \AA$ and its length lies between around $200 \mathrm{~nm}$ to more than $1000 \mathrm{~nm}$ (Tournassat \& Steefel, 2015). The number of stacked layers of a kaolinite tactoid ranges from 10 to more than 200 whereas this number ranges between 1 and 2, 6 and 10, and 5 and 20 for Na-montmorillonite, Ca-montmorillonite and illite, respectively (Tournassat et al., 2015; Tournassat \& Steefel, 2015; Leroy et al., 2017a). The height of a kaolinite tactoid ranges between 7 and $150 \mathrm{~nm}$ and the height of an illite and montmorillonite tactoid lies between 5 and $20 \mathrm{~nm}$, and, 1 and $10 \mathrm{~nm}$, respectively (Hassan et al., 2006; Tournassat et al., 2011; Tournassat \& Steefel, 2019). It results that the total specific surface area of a kaolinite tactoid is considerably lower than the total specific surface area of an illite and montmorillonite tactoid (typically, 10-20 $\mathrm{m}^{2} / \mathrm{g}$ versus $100-200 \mathrm{~m}^{2} / \mathrm{g}$ and $750-800 \mathrm{~m}^{2} / \mathrm{g}$, respectively).

Consequently, clay minerals generally present a high aspect ratio with different morphologies: kaolinite and well-crystallized illite have a tendency toward hexagonal and elongated hexagonal morphologies respectively, whereas montmorillonite and less well-crystallized illite have mostly irregular platy or lath-shaped morphologies. The surface charge of the lateral (or edge) surface of kaolinite, illite and montmorillonite (to a lesser extent due to the influence of the basal surface) are controlled by the aluminol and silanol ( $>\mathrm{Al}-$ $\mathrm{OH}$ and $>$ Si-OH) surface sites and are thus sensitive to salinity and pH (Tombácz \& Szekeres, 2006). When salinity and $\mathrm{pH}$ increase, the charge on these surfaces is generally more negative due to the $>$ Si-O- surface sites. On the other hand, the basal surface of illite and montorillonite is permanently negative and less sensitive to salinity and $\mathrm{pH}$ because it mainly results from the isomorphic substitutions in the crystal lattice (e.g., $\mathrm{Si}^{4+}$ by $\mathrm{Fe}^{3+}$ or $\mathrm{Al}^{3+}$ ions in the T-sheet or $\mathrm{Al}^{3+}$ by $\mathrm{Mg}^{2+}$ or $\mathrm{Fe}^{2+}$ ions in the O-sheet). Most of the isomorphic substitutions in these minerals occur in the O-sheet. Because the specific surface area of the basal surface of these 2:1 clays is more than one order of magnitude higher than the specific surface area of the lateral surface (typically $760 \mathrm{~m}^{2} / \mathrm{g}$ vs $20 \mathrm{~m}^{2} / \mathrm{g}$ ) (Tournassat et al., 2011), the basal surface may control the surface electrical properties of illite and montmorillonite. The CEC method can be used to measure the surface properties and then the surface charge of illite and montmorillonite, if the specific surface area is known (Okay et al., 2014). For kaolinite, the CEC is very sensitive to $\mathrm{pH}$ and salinity due to the $\mathrm{pH}$ and salinity dependent surface charge of the lateral sur- 
face. When a clay particle is put in water, an EDL mostly made of counterions builds up to compensate the external negative surface charge (Leroy et al., 2015; Tsujimoto et al., 2013). The internal negative surface charge of montmorillonite is compensated by cations in the interlayer space. The pore space is then made of the EDL and the free electrolyte. The EDL is thought to be composed of two portions, the Stern and the diffuse layer. The Stern layer is only made of counterions (cations for clays) and is thought to be fixed to the surface of the mineral (see Figure 1). The diffuse layer is made mostly of counter-ions that are more mobile than those of the Stern layer. When a clay particle and its surrounding electrolyte is submitted to a frequency dependent electrical field (for frequencies typically lower than $1 \mathrm{MHz}$ ), cations and anions around the clay particle separate, giving rise to different types of polarization mechanisms.

In the literature, three different polarization mechanisms have been proposed for clay samples in the $\mathrm{mHz}$ to the $\mathrm{kHz}$ frequency range: Maxwell-Wagner polarization, EDL polarization, and membrane polarization (e.g., Kemna et al., 2012; Chen \& Or, 2006; Leroy \& Revil, 2009; Bücker \& Hördt, 2013; Bücker et al., 2019). The Maxwell-Wagner polarization mechanism is due to a charge build-up at boundaries between phases with different electrical properties (conductivity, permittivity) in geologic materials and happens at the highest frequencies (in the $\mathrm{kHz}$ range) for SIP. The EDL polarization happens when ions in the Stern and diffuse layers migrate around the surface of the mineral guided on the orientation of the time varying external electric field, leading to a charge separation in the EDL at the particle scale (Leroy et al., 2017a). This polarization mechanism typically occurs at the mid frequencies for SIP (below the kHz range). Finally, the membrane polarization mechanism happens when pore throats block electrical charges (anions for clays, due to their negative electrical charge) mobilizing due to repulsive EDLs and a time varying external electric field, and thus charges separate in ion selective zones. This polarization mechanism happens in the lowest frequencies for SIP (typically in the $\mathrm{mHz}$ to the $\mathrm{Hz}$ range). With all these polarization mechanisms the question is open on what is the active polarization mechanism in clay samples at a given frequency of the injected sinusoidal electrical field.

\subsection{Background on spectral induced polarization}

The SIP geophysical method consists of a sinusoidal electric current injection in a rock sample and the measurement of a resulting electrical potential difference between 
two electrodes at multiple frequencies (from $\mathrm{mHz}$ to $\mathrm{kHz}$ ). In addition to the electrical conductivity (or resistivity, $\rho^{*}=1 / \sigma^{*}$ ) of the sample, the phase-lag between injected and measured signal gives information about the petrophysical and surface electrical properties of clay samples at the pore scale (e.g., Leroy et al., 2017a; Kemna et al., 2012; Revil et al., 2012).

The frequency dependent complex conductivity $\sigma^{*}(\omega)$ is inferred from SIP. The angular frequency $\omega(\mathrm{rad} / \mathrm{s})$ is related to the frequency $f(\mathrm{~Hz})$ by $\omega=2 \pi f$. There are two ways to express the complex conductivity, either by real $\sigma^{\prime}\left(\mathrm{S} \mathrm{m}^{-1}\right)$ and imaginary components $\sigma^{\prime \prime}\left(\mathrm{S} \mathrm{m}^{-1}\right)$, or amplitude $|\sigma|\left(\mathrm{S} \mathrm{m}^{-1}\right)$ and phase $\varphi(\mathrm{rad})$ :

$$
\sigma^{*}(\omega)=|\sigma| e^{i \varphi}=\sigma^{\prime}+i \sigma^{\prime \prime}
$$

where $i=\sqrt{-1}$ represents the imaginary unit. The resulting electric signal of a rock sample depends on the electrical properties of the pore water and the rock matrix itself. Following Waxman \& Smits (1968), we assume then that the measured electrical conductivity (a complex quantity) is a result of the bulk pore water electrical conductivity $\left(\sigma_{w}\right)$ in the rock acting in parallel to the surface conductivity $\left(\sigma_{\text {surf }}^{*}\right)$ of the geologic material:

$$
\sigma^{*}=\frac{\sigma_{w}}{F}+\sigma_{\text {surf }}^{*},
$$

where $F$ is the electrical formation factor, sensitive to the electrically connected porosity and the shape of the grains. For clays, surface conduction is particularly strong due to their high specific surface area and surface charge, resulting in a strong EDL (Leroy \& Revil, 2004). Weller et al. (2013) took equation 2 and proposed a linear relation between the real part of the measured conductivity, water conductivity, and surface conductivity:

$$
\sigma_{\text {surf }}^{\prime}\left(\sigma_{w}\right)=\sigma^{\prime}\left(\sigma_{w}\right)-\frac{\sigma_{w}}{F} .
$$

Following the notation of Weller et al. (2013), we have:

$$
\sigma^{\prime \prime}=\sigma_{\text {surf }}^{\prime \prime} .
$$


Börner (1992) proposes to link the real and imaginary surface components as:

$$
l=\frac{\sigma_{\text {surf }}^{\prime \prime}}{\sigma_{\text {surf }}^{\prime}} .
$$

\subsection{Double-Pelton phenomenological model}

In order to model SIP data there are several types of models available, some are physical models and some are phenomenological. Physical models are often complex and require a thorough knowledge of a plethora of physical and chemical properties of the rock sample in question. Phenomenological models are able to reproduce large datasets and do not require much knowledge on the physical and chemical properties of the rock sample that is being studied. We use a phenomenological double-Pelton model to fit our data. We use one Pelton model to describe the complex conductivity (the inverse of the complex resistivity) of the clay and the other Pelton model to explain the high frequency signal due to inductive and capacitive noise and also clay polarization. Our double-Pelton model consists of two individual Pelton (Pelton et al., 1978) electrical signals summed up together. The double-Pelton model originates from the Cole-Cole and Debye models (Cole \& Cole, 1941). The double-Pelton model is defined by:

$$
\rho^{*}(\omega)=\rho_{0}\left[1-m_{1}\left(1-\frac{1}{1+\left(i \omega \tau_{1}\right)^{c_{1}}}\right)-m_{2}\left(1-\frac{1}{1+\left(i \omega \tau_{2}\right)^{c_{2}}}\right)\right],
$$

where $\rho(\Omega \cdot \mathrm{m})$ is the electrical resistivity of the sample (inverse of the electrical conductivity $\sigma), c(-)$ is the Cole-Cole exponent, $\tau$ (s) refers to the relaxation time, and $m(\mathrm{mV} / \mathrm{V})$ is the chargeability of the material. In general, $\rho_{0}$ is thought of as a direct current (DC) or low frequency term. In the case of $\mathrm{c}=0.5$, the Pelton model becomes a Warburg model. Therefore, when in equation 6 we have $c_{1}=0.5$ and $c_{2}=0.5$, we obtain a double-Warburg model.

\section{Materials and methods}

\subsection{CEC and XRD of clay samples}

We performed the CEC measurements and the X-ray diffraction (XRD) characterization of all the clay types used in this work, to have the surface properties and the mineralogical composition of the samples. We present the results of the XRD analysis 
Table 1. Results of XRD analysis, showing the exact mineral content of each clay sample.

\begin{tabular}{|c|c|c|c|c|c|c|c|c|c|}
\hline Clay sample & $\begin{array}{c}\text { Smectite } \\
\%\end{array}$ & $\begin{array}{c}\text { Illite } \\
\%\end{array}$ & $\begin{array}{c}\text { Kaolinite } \\
\%\end{array}$ & $\begin{array}{c}\text { Gypsum } \\
\%\end{array}$ & $\begin{array}{c}\text { Quartz } \\
\%\end{array}$ & $\begin{array}{c}\text { Microcline } \\
\%\end{array}$ & $\begin{array}{c}\text { Albite } \\
\%\end{array}$ & $\begin{array}{c}\text { Calcite } \\
\%\end{array}$ & $\begin{array}{c}\text { Magnetite } \\
\%\end{array}$ \\
\hline $\begin{array}{c}\text { Kaolinite } \\
\text { sample }\end{array}$ & 4 & 3 & 84 & & 10 & & & & \\
\hline $\begin{array}{c}\text { Illite } \\
\text { sample }\end{array}$ & & 67 & 10 & & & 10 & & 12 & \\
\hline $\begin{array}{c}\text { Green } \\
\text { mont. sample }\end{array}$ & 90 & 1 & & $t r^{*}$ & 1 & 3 & 1 & 4 & \\
\hline $\begin{array}{c}\text { Red } \\
\text { mont. sample }\end{array}$ & 66 & & & & 11 & 18 & 3 & & 1 \\
\hline
\end{tabular}

$t r^{*}:$ traces.

in Table 1. As for the CEC results, we obtained: $22 \mathrm{meq} / 100 \mathrm{~g}$ for the kaolinite sample, $47 \mathrm{meq} / 100 \mathrm{~g}$ for the illite sample, $132 \mathrm{meq} / 100 \mathrm{~g}$ for the green montmorillonite sample, and $135 \mathrm{meq} / 100 \mathrm{~g}$ for the red montmorillonite sample. From Table 1, we see that none of our clay samples are $100 \%$ pure. The XRD measurements were obtained using a Philips Xpert machine from clay powder and glycolated samples. The bulk clay powder samples were quantitatively analyzed with randomly oriented preparations following Brindley \& Brown (1980) and Moore \& Reynolds (1989). Furthermore, following the modified Chung method (Chung, 1974; Hillier, 2003) an analysis on glycolated oriented preparations was done in order to correct the measurements on the clay powder samples. The CEC measurement consists of replacing a cation present on the clay surface with another cation (Ma \& Eggleton, 1999). Methods differ on the exchanged cation, the exchange solution (according to the AFNOR standard NF X31-108 and Khaled \& Stucki, 1991), and if there are consecutive exchanges in the procedure (Ciesielski \& Sterckeman, 1997; Meier \& Kahr, 1999). For the CEC measurements presented in this paper, we determined the amount of recovered $\mathrm{Mg}^{2+}$ ions after a second exchange (Khaled \& Stucki, 1991). 


\subsection{Preparation of clay samples}

We developed a laboratory protocol that allowed us to have clay mixtures we could knead and place inside a sample holder, while ensuring a good reproducibility of the data. Plasticity is our criteria for a parameter to keep between all clay types, salinities and measurements. When we talk about plasticity, we need to take a look at the Atterberg limits in clays. The liquid and plastic limits are water contents that mark the limits of plastic behavior of clays (White, 1949). We chose a water content within those limits for each clay, to avoid a clay mixture too liquid (more water than the liquid limit), or a sample too dry that crumbles into pieces (smaller water content than the plastic limit). Wagner (2013) presents a table of liquid and plastic limits for illite, kaolinite, smectites, and others. Note that Mitchell \& Soga (2005) explain that the availability of ions and the valence of the ions present in the pore water of the clay samples may affect these limits. As presented in Table 2, we see a decrease of porosity at the highest salinities in our clay samples, in accordance with Mitchell \& Soga (2005).

Figure 2 describes the procedure used to prepare the clay samples. In order to obtain the adequate plasticity, we first combine water and clay powder at higher water contents than the objective (Figure 2a and b). We left the clay powder in contact with water for at least 24 hours to have a good imbibition process, and we then mix the whole mixture mechanically using a drill until we reach a homogeneous mixture (Figure 2c). In order to obtain the desired water content, we eliminate the water excess through evaporation by letting the clay mixture dehydrate on a polyurethane foam (Figure 2d). We use a polyurethane foam to have a homogeneous evaporation process, that is, to allow evaporation from the bottom, top and sides of the clay mixture. The mass of the mixture is monitored at every step to determine the evolution of water content at each step of the process. After obtaining the desired water content, we take the clay mixture out of the foam, knead it and locate it in our sample holder (Figure 2e). Once in place, we perform the SIP measurement of the clay sample twice, from $1 \mathrm{mHz}$ to $20 \mathrm{kHz}$ (see the following section and Figure 2f). We acknowledge that a total chemical equilibrium might not be achieved when measuring the SIP signal in the clay samples, but we assume that the difference between the SIP signal we measure and a true equilibrated sample is negligible. After the measurements are over, we take out the sample from the sample holder and dry it in an oven at $105^{\circ} \mathrm{C}$ during $25 \mathrm{~h}$ (Figure $2 \mathrm{~g}$ ). By measuring the mass at every step of the process, we can calculate the water content (presented in Table 2) at each step and therefore de- 
termine the porosity of our clay sample during the SIP measurement. The calculated porosities of the clay mixtures are presented in Table 2. These porosities help us keep a check on the water vs clay powder ratios of our samples. The porosity calculations present some experimental uncertainties, these porosity values are a good estimate but should not be over-interpreted.

Note that as the water content changed in the samples, so did the salinities. We originally started all samples with five different salinities: De-ionized water (D.W.), $1 \times 10^{-3}$, $1 \times 10^{-2}, 1 \times 10^{-1}$, and $1 \mathrm{M}(\mathrm{mol} / \mathrm{L})$ of $\mathrm{NaCl}$. To account for the water content decrease due to the evaporation procedure, we recalculated the salinities in our sample during the SIP measurements for all the salinities from $1 \times 10^{-3}$ to $1 \mathrm{M}$ of $\mathrm{NaCl}$. Table 2 presents the corrected salinities using a simple proportion equivalence. From these postdehydration salinity values we calculated the bulk water electrical conductivity, following the procedure proposed in Leroy et al. (2015), using:

$$
\sigma_{w}=e 10^{3} N_{A} \sum_{i=1}^{N} z_{i} \beta_{i}^{w} C_{i}^{w},
$$

where $\beta_{i}^{w}$ (in $\mathrm{m}^{2} \mathrm{~s}^{-1} \mathrm{~V}^{-1}$ ) is the ionic mobility of an ion $i$ in the bulk water, $C_{i}^{w}$ (in mol $\left.\mathrm{dm}^{-3}\right)$ is its concentration, and $z_{i}$ is its valence. Also, $N_{A}$ is the Avogadro number $(6.022 \times$ $\left.10^{23} \mathrm{~mol}^{-1}\right)$, and e is the elementary charge $\left(1.602 \times 10^{-19} \mathrm{C}\right)$. It is worth noting that the ionic mobility values used in equation 7 have been corrected for the temperature and salinity, as presented in Leroy et al. (2015). It should be noted that the low-salinity water conductivity values may be underestimated because we do not consider clay dissolution as well as cation leaching from the interlayer space for the calculation of the ion concentrations.

\subsection{SIP measurement setup}

We conducted the SIP measurements on the clay samples using the SIP-FUCHS III equipment (Radic Research, www.radic-research.de). The setup for the measurements is presented in Figure 3a. The SIP-FUCHS III sends a sinusoidal current into the sample through the injection unit and then the so-called current electrodes $(\mathrm{C} 1$ and $\mathrm{C} 2$ in Figure $3 \mathrm{~b}$ ) by imposing a chosen potential difference. The second unit measures the resulting voltage through the so-called potential electrodes (P1 and P2 in Figure 3b). The communication between the units (injection and measurement) and the system is done 
Table 2. Post-dehydration calculated salinities, porosities, and gravimetric water contents $\left(m_{\text {fluid }} / m_{\text {solid }}\right)$ for all the SIP-measured clay samples.

\begin{tabular}{|c|c|c|c|c|c|}
\hline Initial Salinity & (D.water) & $\left(10^{-3} \mathrm{M} \mathrm{NaCl}\right)$ & $\left(10^{-2} \mathrm{M} \mathrm{NaCl}\right)$ & $\left(10^{-1} \mathrm{M} \mathrm{NaCl}\right)$ & $(1 \mathrm{M} \mathrm{NaCl})$ \\
\hline Clay type & $\begin{array}{l}\text { Final salinity } \\
\qquad(\mathrm{M} \mathrm{NaCl})\end{array}$ & $\begin{array}{l}\text { Final salinity } \\
\qquad(\mathrm{M} \mathrm{NaCl})\end{array}$ & $\begin{array}{l}\text { Final salinity } \\
\qquad(\mathrm{M} \mathrm{NaCl})\end{array}$ & $\begin{array}{l}\text { Final salinity } \\
\qquad(\mathrm{M} \mathrm{NaCl})\end{array}$ & $\begin{array}{c}\text { Final salinity } \\
\qquad(\mathrm{M} \mathrm{NaCl})\end{array}$ \\
\hline $\begin{array}{l}\text { Kaolinite } \\
\text { sample }\end{array}$ & D.W. & $1.53 \times 10^{-3}$ & $1.54 \times 10^{-2}$ & $1.91 \times 10^{-1}$ & 1.76 \\
\hline $\begin{array}{c}\text { Illite } \\
\text { sample }\end{array}$ & D.W. & $1.92 \times 10^{-3}$ & $1.80 \times 10^{-2}$ & $1.82 \times 10^{-1}$ & 1.91 \\
\hline $\begin{array}{c}\text { Green montmorillonite } \\
\text { sample }\end{array}$ & D.W. & $1.39 \times 10^{-3}$ & $1.53 \times 10^{-2}$ & $1.46 \times 10^{-1}$ & 1.54 \\
\hline $\begin{array}{l}\text { Red montmorillonite } \\
\text { sample }\end{array}$ & D.W. & $1.64 \times 10^{-3}$ & $1.71 \times 10^{-2}$ & $1.54 \times 10^{-1}$ & 1.51 \\
\hline Clay type & Porosity & Porosity & Porosity & Porosity & Porosity \\
\hline $\begin{array}{c}\text { Kaolinite } \\
\text { sample }\end{array}$ & 0.54 & 0.59 & 0.57 & 0.56 & 0.47 \\
\hline $\begin{array}{c}\text { Illite } \\
\text { sample }\end{array}$ & 0.52 & 0.56 & 0.54 & 0.56 & 0.42 \\
\hline $\begin{array}{c}\text { Green montmorillonite } \\
\text { sample }\end{array}$ & 0.65 & 0.68 & 0.68 & 0.71 & 0.57 \\
\hline $\begin{array}{l}\text { Red montmorillonite } \\
\text { sample }\end{array}$ & 0.67 & 0.62 & 0.61 & 0.62 & 0.51 \\
\hline
\end{tabular}

Clay type Water content

0.48

0.49

sample

\section{Kaolinite}

sample

Illite

0.51

0.55

0.54

0.44

Green montmorillonite

$$
\text { sample }
$$

0.96

0.91

0.93

0.85

Red montmorillonite

$$
\text { sample }
$$




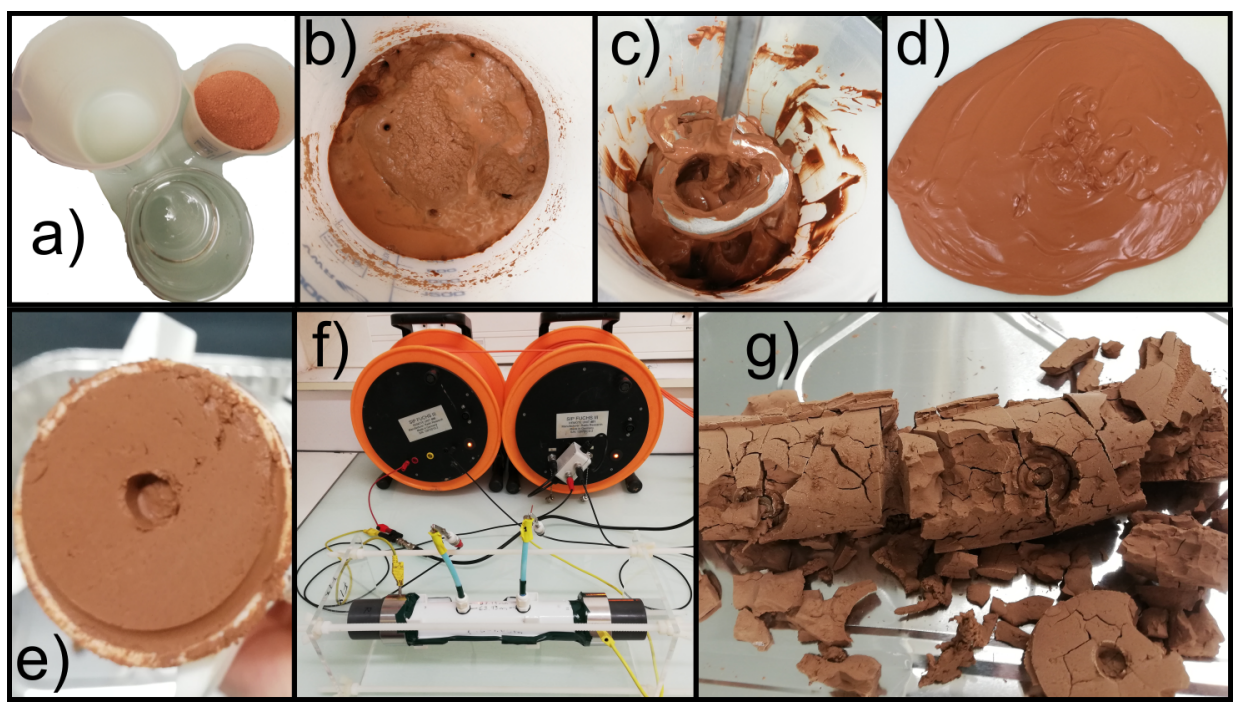

Figure 2. Laboratory protocol to create clay samples: a) Combination of clay powder and water. b) Saturation of clay powder for at least $24 \mathrm{~h}$. c) Homogenization of mixture with drill. d) Excess water evaporation until correct plasticity is reached. e) Setting clay in sample holder. f) SIP measurements. g) Clay sample drying.

through optic cables to reduce electromagnetic noise. The SIP-FUCHS III outputs the amplitude of the measured impedance $(\Omega)$, the phase shift between injected and measured signal (mrad), and their respective errors, for each measured frequency.

The current electrodes $\mathrm{C} 1$ and $\mathrm{C} 2$ are stainless steel cylinders that we use also as covers for the sample holder, while we use home-made non-polarizable electrodes for P1 and P2. We made our own $\mathrm{Cu}-\mathrm{CuSO}_{4}$ non-polarizable electrodes, following the procedure proposed by Kremer et al. (2016). They consist of a copper wire inserted in a plastic tube filled with a saturated solution of copper sulfate and gelatin, plugged by a porous filter at the bottom. We used a near cylindrical sample holder of length $22.9 \mathrm{~cm}$ and radius $2.1 \mathrm{~cm}$, with electrode separation of $7.4 \mathrm{~cm}$, that is separated roughly by a third of the sample holder's total length (Figure 3b); this pseudo-Wenner configuration has been used previously by Ghorbani et al. (2009), and Jougnot et al. (2010). The geometrical factor to convert measured impedances to conductivities has been determined using finite elements numerical methods, this approach has been used previously by Jougnot et al. (2010). 

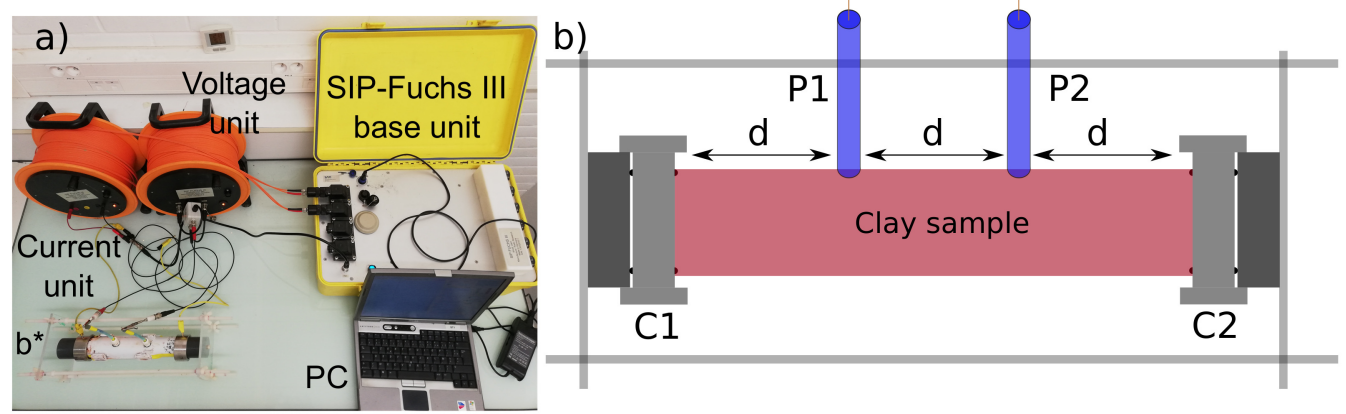

Figure 3. a) Laboratory set-up for SIP measurements on our clay samples with the sample holder, injecting and measuring units (orange), SIP-FUCHS III, and a computer to store the data. b) Sample holder sketch with the external structure. C1 and C2 are two cylindrical plates, our current electrodes that inject a sinusoidal electric current. P1 and P2 are a pair of nonpolarizable electrodes that measure the resulting electrical potential difference, they are equally distanced from the current electrodes, making a pseudo-Wenner array.

We created an external structure to hold the sample holder (Figure $3 \mathrm{~b}$ ) in order to achieve repeatability in our measurements. Indeed, we needed the ability to close the sample holder at the exact same position and with the same pressure between measurements. As repeatability test, we built two identical sample holders, made two individual green montmorillonite samples, and measured the SIP signal in both samples. The repeatability of the measurements shows a $4.7 \%$ difference on the real part of the electrical conductivity and a $0.47 \%$ difference on the imaginary part at $1.46 \mathrm{~Hz}$. For the whole spectrum, we see a maximum percentage difference of $4.8 \%$ on the real part of the electrical conductivity (at $2.9 \mathrm{mHz}$ ) and $11.89 \%$ for the imaginary part (at $45.8 \mathrm{mHz}$ ). In average, for the whole spectrum, we see a difference of $4.6 \%$ for the real part of the spectrum, and $1.5 \%$ for the imaginary part. See the supplementary information file, to visualize the repeatability test. We acknowledge that the difference between the real part of the conductivity between both samples is surprising (although negligible). We think that such difference lies on the fact that we are dealing with two different clay samples in two different sample holders. A minimal difference between these two will correspond to a minimal difference between their signals. 


\subsection{Optimization of the double-Pelton model}

For the optimization procedure, we use our SIP data as input, that is, conductivity amplitude $\left(\mathrm{S} \mathrm{m}^{-1}\right)$ and phase (rad), and then fit a double-Pelton model (see equation 6). In this paper, we optimize for seven parameters: $\rho_{0}, m_{1}, m_{2}, \tau_{1}, \tau_{2}, c_{1}$, and $c_{2}$. The cost function is:

$$
\Phi=\frac{\sum_{i=1}^{N_{a}}\left(A_{\text {mes }}^{i}-A_{\text {mod }}^{i}\right)^{2}}{\sum_{i=1}^{N_{a}}\left(A_{\text {mes }}^{i}-\left\langle\mathbf{A}_{\text {mes }}\right\rangle\right)^{2}}+\frac{\sum_{i=1}^{N_{p}}\left(P_{\text {mes }}^{i}-P_{\text {mod }}^{i}\right)^{2}}{\sum_{i=1}^{N_{p}}\left(P_{\text {mes }}^{i}-\left\langle\mathbf{P}_{\text {mes }}\right\rangle\right)^{2}},
$$

where, $A_{\text {mes }}$ represents the measured amplitude vector, $\left\langle\mathbf{A}_{\text {mes }}\right\rangle$ represents the mean of the measured amplitude vector, $A_{m o d}$, the modeled or calculated amplitude vector, via the double-Pelton model, $N_{a}$ is the number of amplitude data points that have been preserved, $P_{\text {mes }}$ is the measured phase vector, $\left\langle\mathbf{P}_{\text {mes }}\right\rangle$ is the mean of the measured phase vector, $P_{\text {mod }}$ is the modeled or calculated phase vector, and $N_{p}$ is the number of phase data points that have been kept. The strategy we used was to first optimize with a simulated annealing approach, that has been explained in detail in Maineult (2016). For the parameters $m_{1}, m_{2}, c_{1}$, and $c_{2}$, we let them vary between [0 - 1], for $\rho_{0}$ we usually use $[\bar{\rho} \pm(0.2 \cdot \bar{\rho}) \Omega \cdot m]$, for $\tau_{1}$ we usually use $\left[10^{-3}-10^{6}\right] \mathrm{s}$, and finally for $\tau_{2}$ we use $\left[10^{-10}\right.$ $10^{1} \mathrm{~s}$. Here, $\bar{\rho}$ is the arithmetic mean electrical resistivity for all frequencies. We later optimize the double-Pelton parameters using a simplex optimization procedure (Caceci \& Cacheris, 1984). This same strategy has been used in Maineult et al. (2017). As input of the simplex code we use our measured SIP data (amplitude and phase) and as initial model we use the result of the simulated annealing method. The simulated annealing step allows us to explore the parameter space preventing to get trapped in a local minimum, but this is done in a discrete manner. When we know the vicinity of the solution, we use the Simplex optimization procedure to refine the solution.

Moreover, we fixed a double-Warburg model for the red and green montmorillonite samples, as well as the kaolinite sample. A double-Warburg model is a double-Pelton model but with $c_{1}=0.5$ and $c_{2}=0.5$. In the case of these three types of clay samples, we turned the optimization code and obtained values of $c_{1}$ and $c_{2}$ near 0.5 . Therefore, we opted that for these three types of clay samples, we would fix $c_{1}$ and $c_{2}$, and we would only optimize for the remaining five parameters, that is: $\rho_{0}, m_{1}, m_{2}, \tau_{1}$, and $\tau_{2}$. It is worth mentioning that we tried fixing $c_{1}$ and $c_{2}$ for the illite sample as we also obtained val- 
ues near 0.5 , but we obtained poor fits with $c_{1}=0.5$ and $c_{2}=0.5$. We assume then that the illite sample does not behave as a double-Warburg, but as a double-Pelton. The rest of the clay samples (kaolinite, red and green montmorillonite samples) do behave as double-Warburg models. The results of our fits are presented later on in this article, in Table 4

\subsection{Differentiation of clay minerals}

In order to compare our SIP datasets, we calculated the normalized measured conductivity differences $\left(\Delta \sigma_{N}^{\prime}\right.$ or $\left.\Delta \sigma_{N}^{\prime \prime}\right)$ between each clay type for every salinity at $1.46 \mathrm{~Hz}$, for both the real and imaginary parts of the complex conductivity. We chose $1.46 \mathrm{~Hz}$ because frequencies near $1 \mathrm{~Hz}$ represent a widely used choice in geophysics (Zanetti et al., 2011). Also, as it will be presented in the results and discussion sections, the local maximum polarization phenomena happens near $10^{0} \mathrm{~Hz}$. To choose this particular frequency, we also took into account that the highest measured errors in the data happened at the lowest frequencies ( $\mathrm{mHz}$ range), because less stacking is possible, due to the long time periods for each measurement. The noisiest data happened at the highest frequencies (kHz range). Indeed, according to Huisman et al. (2016) the electromagnetic coupling effects happen at the highest frequency range of our SIP measurements, in the $\mathrm{kHz}$ range. Therefore, when choosing near $1 \mathrm{~Hz}$, we should get the most accurate data. We calculate $\Delta x_{N}$ values between each clay type at $1.46 \mathrm{~Hz}$, for the datasets shown in Figure 4 . To calculate the $\Delta x_{N}$ we use:

$$
\Delta x_{N}(f=1.46 \mathrm{~Hz})=100 \times \frac{x_{1}-x_{2}}{\frac{x_{1}+x_{2}}{2}},
$$

where $x_{N}, x_{1}$ and $x_{2}$ can be substituted by the real and imaginary parts of the conductivity (so either $\Delta \sigma_{N}^{\prime}$ or $\Delta \sigma_{N}^{\prime \prime}$ ), in such a way that the operation is done either for the real part or the imaginary part of the conductivity, separately. Additionally, $x_{1}$ and $x_{2}$ represent either the real or imaginary part of the conductivity at $1.46 \mathrm{~Hz}$ of an individual type of clay. The idea is to quantify if we are able to distinguish between two different clay minerals in a laboratory setting. That is, if the $\Delta \sigma_{N}^{\prime}$ or $\Delta \sigma_{N}^{\prime \prime}$ value is low (e.g. below 10\%) that means we are hardly able to differentiate two specific clay minerals at the laboratory scale, then at the field scale it would seem impossible to differentiate such clay minerals. Conversely, if we have a high $\Delta \sigma_{N}^{\prime}$ or $\Delta \sigma_{N}^{\prime \prime}$ (e.g. above 100\%) it would 
not mean that we could automatically differentiate two different clay minerals at the field scale.

\section{Results}

We obtained a large SIP dataset in the laboratory. To make our interpretation of this dataset more accessible, we decomposed their analysis into several subsections. First, we will present the complex conductivity values at $1.46 \mathrm{~Hz}$ vs. the calculated water conductivity, to get a quick view of the electric behavior of the clay samples at varying salinities. After that, we present the normalized spectrum of the real part of the complex conductivity per clay type; we show the evolution with salinity. We then present the full spectra of the complex conductivity for all clay samples and all salinities. Afterwards, we present the results of our double-Pelton fits, and the obtained parameters. We finally present a quantitative differentiation between clay samples at the same salinity. We filtered all of our datasets with a $5 \%$ percent filter. That is, if the error of the measured amplitude is larger than $5 \%$, we remove the data point from our dataset. We performed our SIP measurements at five salinities on four types of clay: montmorillonite samples (red and green), a kaolinite sample and an illite sample (see Table 2). Additionally, we performed SIP measurements at three salinities (initially de-ionized water, $1 \times 10^{-2}$, and $1 \mathrm{M}$ of $\mathrm{NaCl}$ ) on two extra types of clay: beige montmorillonite sample and a Boom clay sample. Boom clay is a natural clayrock used for nuclear waste storage (Ortiz et al., 2002). The results of these additional types of clay are shown as supplementary information in this article.

\subsection{Results at varying salinities at $1.46 \mathrm{~Hz}$}

We collected SIP measurements of four different types of clay (red and green montmorillonite samples, an illite sample, and a kaolinite sample) with the SIP-FUCHS III system. We used frequencies from $10^{-3}$ to $10^{4} \mathrm{~Hz}$. The calculated water conductivity values (following equation 7) presented in Figure 4, correspond to those of the post-dehydration salinities (Figures 2d and e). We chose to present the data points at $1.46 \mathrm{~Hz}$, because the highest measured errors and the noisiest data are present at the lowest and highest frequencies, respectively. It should be noted that the low salinity (initially $10^{-3} \mathrm{M} \mathrm{NaCl}$ ) calculated water conductivity values may be underestimated because we did not consider clay dissolution as well as cation leaching from the interlayer space of montmorillonite. 
In Figure 4a we observe that the real conductivity increases with an increase in the conductivity of the fluid saturating our clay mixtures for all salinities for all types of clay. In addition, Figure 4a shows that both montmorillonite samples exhibit higher surface conductivity than the illite and kaolinite samples. Due to their difference in surface electrical properties (see section 2.1), it is a bit surprising to see that the kaolinite and illite samples may have the same surface conductivity here. This may be due to the fact that the kaolinite sample is not pure and contains $4 \%$ in weight of more conducting smectite and $3 \%$ in weight of more conducting illite (see Table 1).

With the imaginary conductivity we see a different behavior. For the red and green montmorillonite samples, we see a peak of the imaginary conductivity at the second to highest salinity (corresponding to a water conductivity in the $10^{0} \mathrm{~S} \mathrm{~m}^{-1}$ range). For the kaolinite and illite samples, we see a similar behavior, however, we see the peak in the range of $10^{-1} \mathrm{~S} \mathrm{~m}^{-1}$ for the water conductivity. The imaginary conductivity amplitude is also roughly one order of magnitude higher for the montmorillonite samples than for other clay samples. Due to their higher CEC and stronger EDL, the montmorillonite samples polarize more than the illite and kaolinite samples. In addition, the zeta potential of Namontmorillonite in a $\mathrm{NaCl}$ solution is higher in magnitude than the zeta potential of illite and kaolinite in a $\mathrm{NaCl}$ solution (Sondi et al., 1996; Leroy \& Revil, 2004; Leroy et al., 2015). Consequently, membrane polarization effects may be higher for Na-montmorillonite than for illite and kaolinite. It results that more salt is necessary to decrease the imaginary conductivity of montmorillonite compared to illite and kaolinite at high salinity. Note that although we collected SIP data at five different salinities, the de-ionized water dataset are not presented in Figure 4. We chose not to present those data points because knowing or controlling the conductivity of the pore water at that salinity proved to be very complex, and out of the scope of this paper. However, the datasets of de-ionized water are presented in the following parts of this paper.

Equation 2 was adjusted to the $\sigma^{\prime}$ values at $1.46 \mathrm{~Hz}$ (for $10^{-3}-1 \mathrm{M} \mathrm{NaCl}$ ) by considering that the formation factor and the surface conductivity are independent from the pore water conductivity. For this adjustment, more weight was attributed to the values for the two highest pore water conductivities as they are expected to be less sensitive to the surface conductivity (see Weller et al., 2013). This procedure provides a single surface conductivity per sample presented in Table 3 and seems to overestimate its values for the lowest pore water conductivity. As expected, we see larger values of $\sigma_{\text {surf }}^{\prime}$ for both 

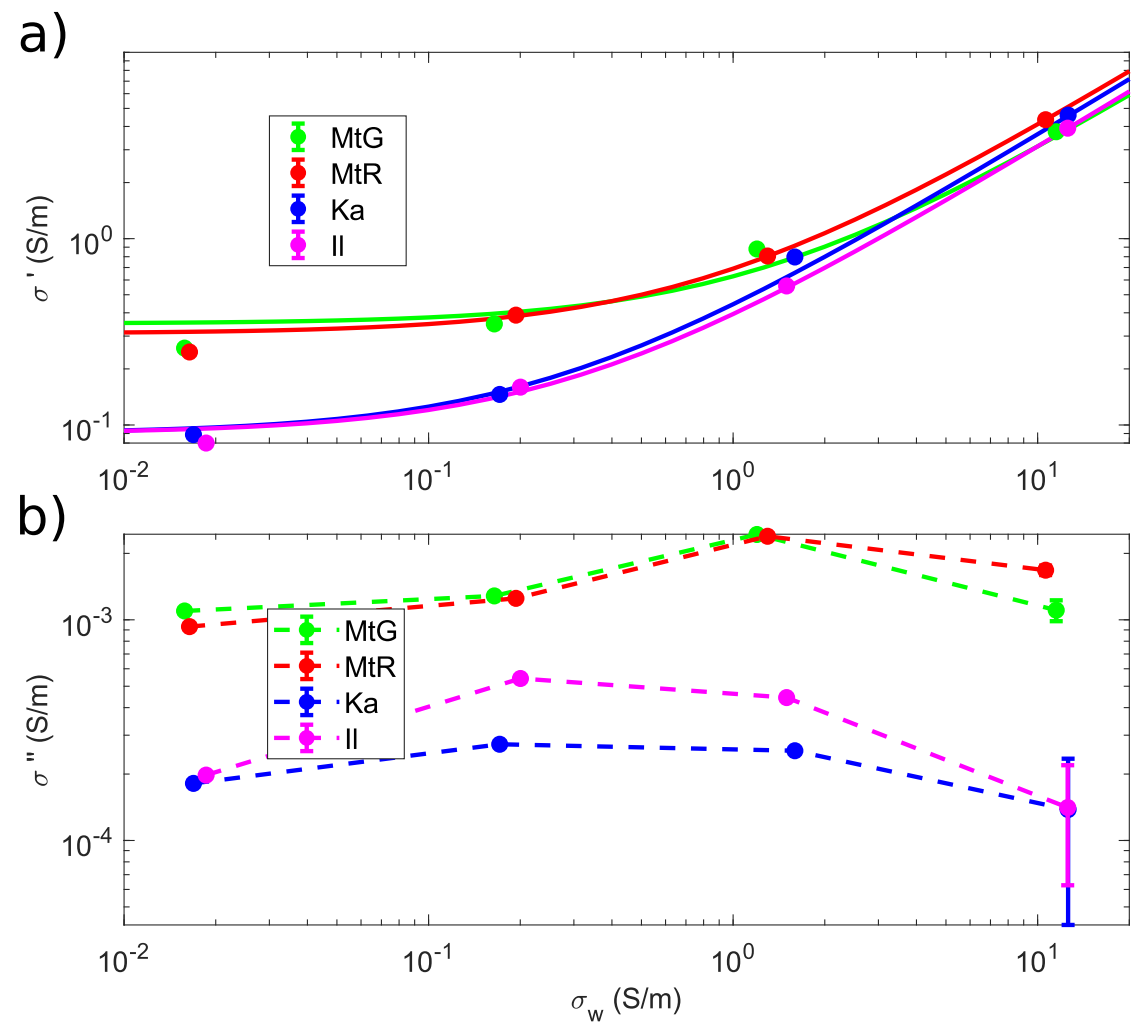

Figure 4. Measured (filled circles) real (a) and imaginary (b) conductivity of the four clay samples as a function of calculated water conductivity, at a frequency of $1.46 \mathrm{~Hz}$. MtG represents the green montmorillonite sample, MtR the red montmorillonite sample, Ka the kaolinite sample, and Il the illite sample. The bold line on (a) is the calculated $\sigma^{\prime}\left(\sigma_{w}\right)$ from equation 2 , the parameters we fit are presented in Table 3. 
Table 3. Formation factors $(F)$ and $\sigma_{\text {surf }}^{\prime}$ fitted from equation 2 for the real conductivity values at $1.46 \mathrm{~Hz}, \mathrm{CEC}$ and specific surface area (Ss) of the clay samples.

\begin{tabular}{ccccc}
\hline Clay type & $F[-]$ & $\sigma_{\text {surf }}^{\prime}\left[\mathrm{Sm}^{-1}\right]$ & $\mathrm{CEC}[\mathrm{meq} / 100 \mathrm{~g}]$ & $\mathrm{Ss}^{*}\left[\mathrm{~m}^{2} / \mathrm{g}, \mathrm{BET}\right]$ \\
\hline $\begin{array}{c}\text { Kaolinite } \\
\text { sample }\end{array}$ & 2.82 & 0.09 & 22 & 16.94 \\
$\quad$ Illite & & & & \\
sample & 3.29 & 0.09 & 47 & 101.60 \\
$\begin{array}{c}\text { Green mont. } \\
\text { sample }\end{array}$ & 3.60 & 0.35 & 132 & 77.71 \\
$\begin{array}{c}\text { Red mont. } \\
\text { sample }\end{array}$ & 2.63 & 0.31 & 135 & 71.09 \\
\hline
\end{tabular}

${ }^{*}$ Specific surface area measured through the BET (Brunauer-Emmett-Teller) method for each sample. BET cannot probe the interlayer space of montmorillonites.

montmorillonite samples, because these clay samples have a more important surface electric charge and specific surface area than the illite or kaolinite samples. We recognise the formation factor values we obtained have some uncertainty and are only meant as a mean of the electrical formation factor for each type of clay sample, as we are dealing with clay muds with varying porosities and not hard rocks with a specific formation factor. We present the $\sigma^{\prime}$ calculated values from the $\sigma_{\text {surf }}^{\prime}$ and $F$ fitted values in Figure 4a. It is worth mentioning that the specific surface areas measured using the BET (BrunauerEmmett-Teller) technique might not be representative of the true values for the montmorillonites mineral. Indeed, previous work from the literature indicate this technique is not able to properly probe interlayer space (e.g., Tournassat et al., 2003; Hassan et al., 2006). In order to do so, other methods such as wet-state methylene blue (MB) should be used (Weller et al., 2015a). Another possibility to better determine the real specific surface area could be through a calculation of the specific surface area based on the XRD characterisation of the samples. According to the literature the specific surface area of montmorillonites should be in the range of $390-780 \mathrm{~m}^{2} / \mathrm{g}$ (see Tournassat et al., 2013). 


\subsection{Normalized real conductivity}

In Figure 5 we show the normalized real conductivity for all clay samples. For normalization value we used the amplitude of the conductivity at $1.46 \mathrm{~Hz}$, per clay type, per salinity. We observe that overall the signal of the normalized real conductivity gets flattened as the salinity increases. In other words, we see less of a change in the normalized real conductivity within the measured frequency range as the salinity of the fluid increases. We interpret this as evidence that at the highest salinity, pore conduction dominates over the surface conduction, and we are able to see this evolution with salinity. The normalized value presented in Figure 5 could be interpreted as a ratio of alternating current (AC) conduction vs. close to direct current (DC) conduction. Even though we see an overall decrease with salinity of $\sigma^{\prime} / \sigma_{1.46}$. This decrease could be interpreted as evidence that the $\mathrm{DC}$ conduction increases faster with salinity than the $\mathrm{AC}$ conduction due to polarization. We used a frequency of $1.46 \mathrm{~Hz}$ as normalization value because, as mentioned previously in the paper, as it is the closest value to $1 \mathrm{~Hz}$; a widely used choice in field geophysics. Also, in field geophysics, the measurements (i.e. electrical resistivity tomography) are thought of as DC measurements. A true DC value would make use of the lowest measured frequency.

\subsection{Effect of the salinity on the spectra}

Figure 6 shows the real conductivity spectra of each clay per salinity, with the doublePelton model superimposed onto the dataset. We see for all of the clay samples that as the salinity increases, the real conductivity also increases. We do however notice that the data seems more dispersed for the kaolinite and illite samples, meaning, the difference between maximum and minimum conductivities seems bigger for the kaolinite and illite samples, than for the montmorillonite samples.

Figure 7 shows the imaginary conductivity spectra of each clay per salinity, with the doublePelton model predictions superimposed onto the dataset. For the montmorillonite samples we see the overall highest polarization at the second to highest salinity. Finally, for the kaolinite and illite samples, we see the highest polarization at the middle salinity $\left(10^{-2}\right.$ $\mathrm{M}$ of $\mathrm{NaCl}$ salinity range), this is better seen for the illite sample.

The errorbars become larger in the highest salinity measurements. This is expected from the measurement itself. Indeed, measuring low phases, that is, very small time differences 

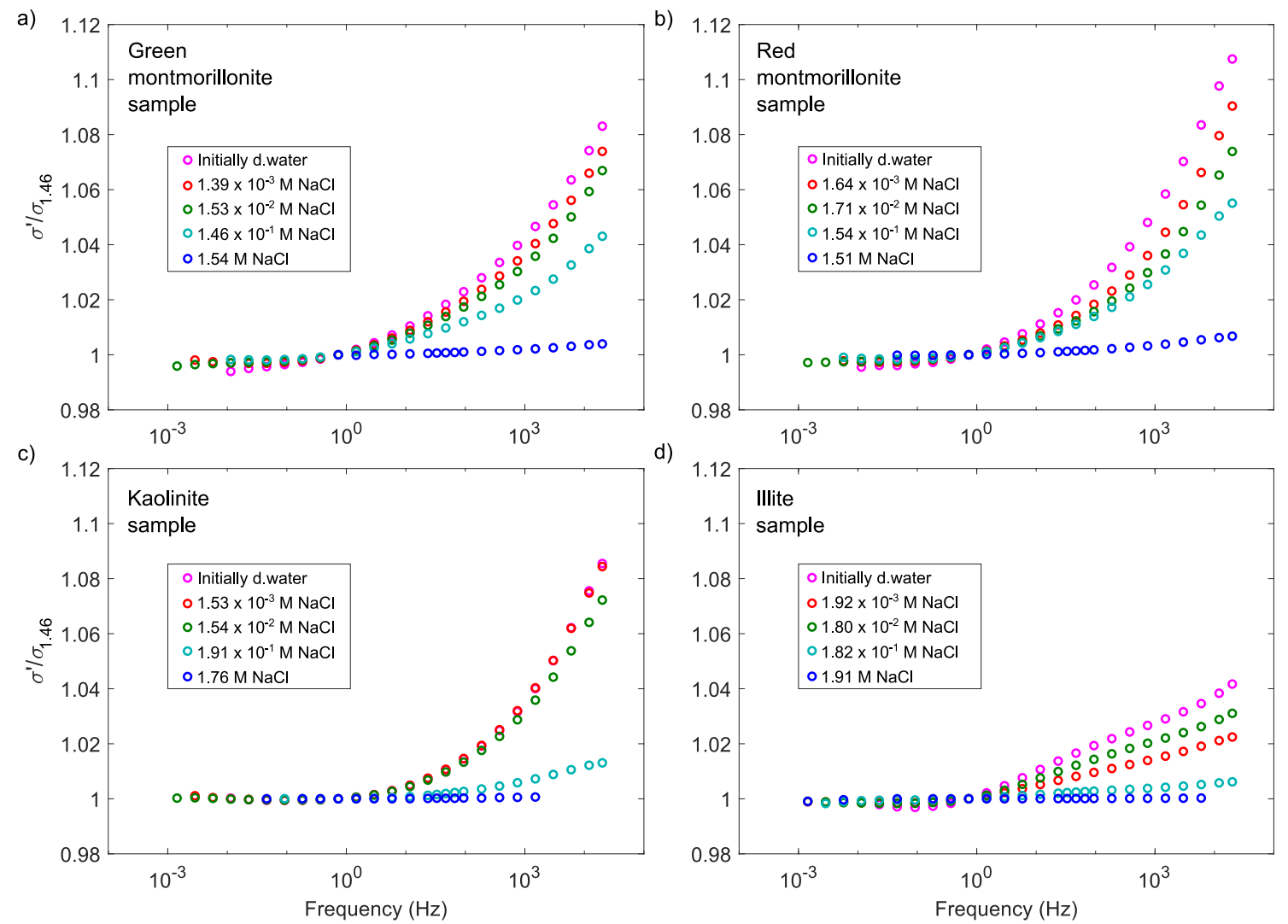

Figure 5. Normalized real conductivity for all salinities per clay type: a) green montmorillonite sample, b) red montmorillonite sample, c) kaolinite sample, and d) illite sample. All these spectra have been normalized by the conductivity amplitude at $1.46 \mathrm{~Hz}$. 

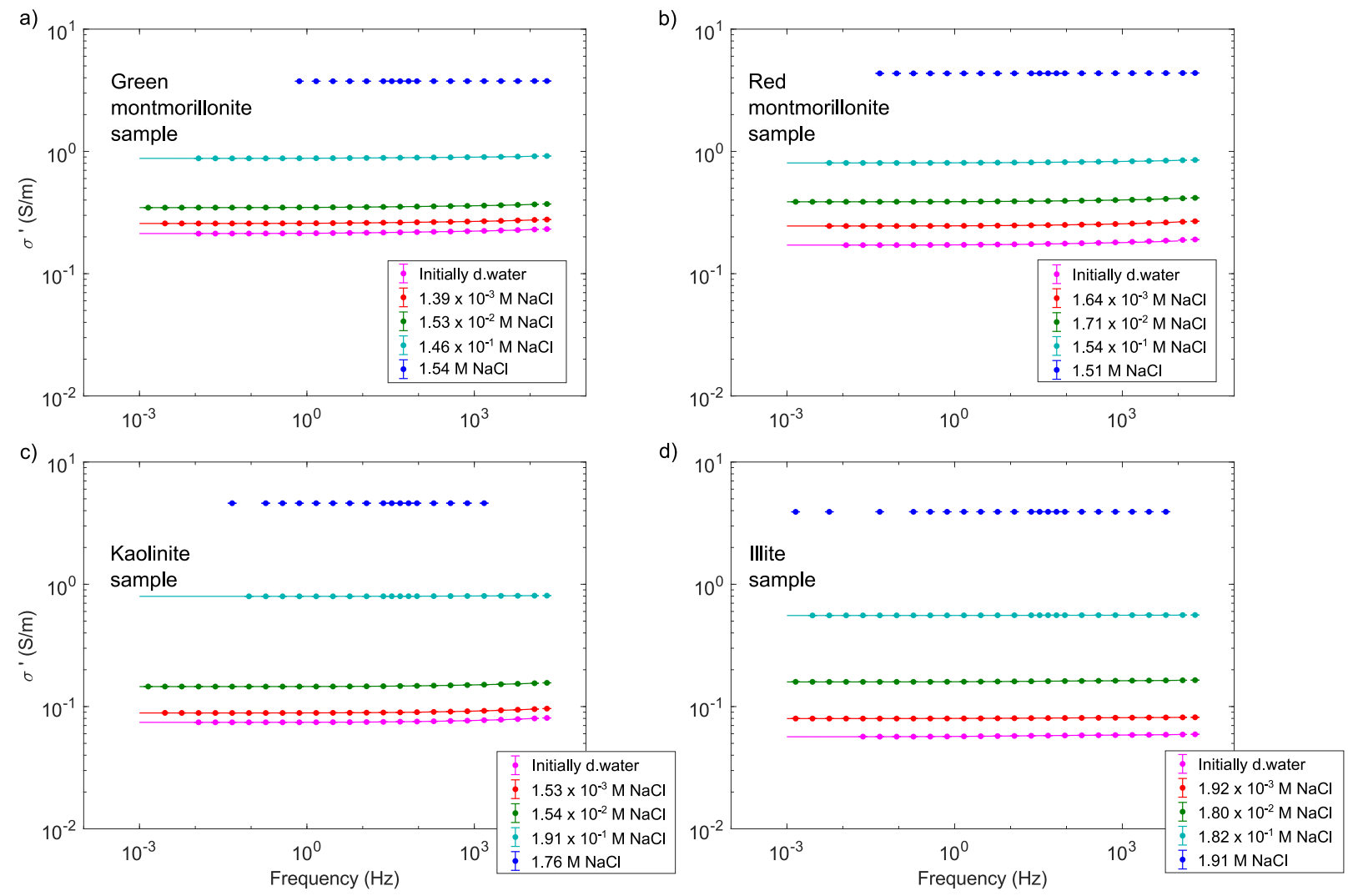

Figure 6. Real part of the complex conductivity per salinity of: a) green montmorillonite sample, b) red montmorillonite sample, c) kaolinite sample, and d) illite sample. The calculated salinity values at which the SIP measurements were collected are presented in the legends of each subplot. Dots with errorbars represent the measured SIP data, and the line represents the double-Pelton model predictions for each dataset. 
a)

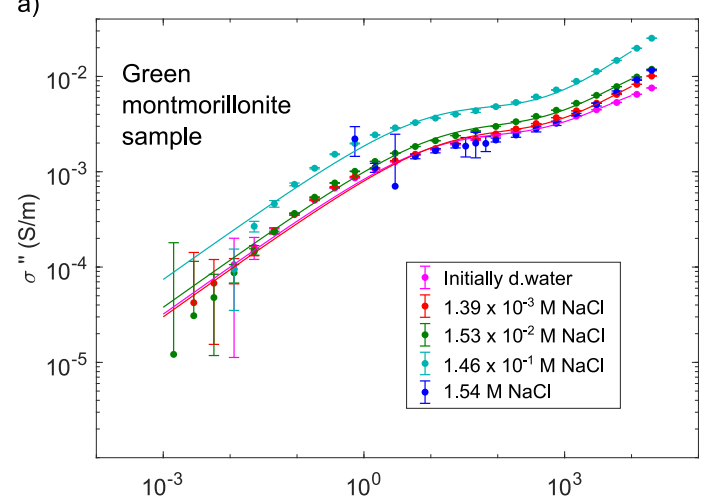

c)

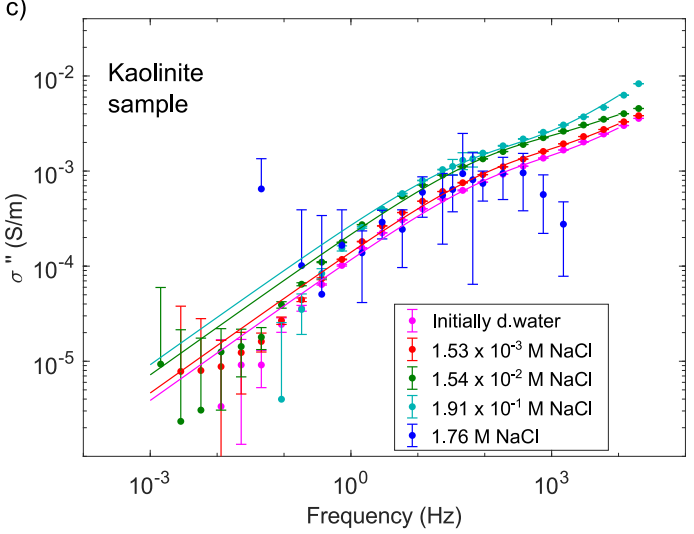

b)

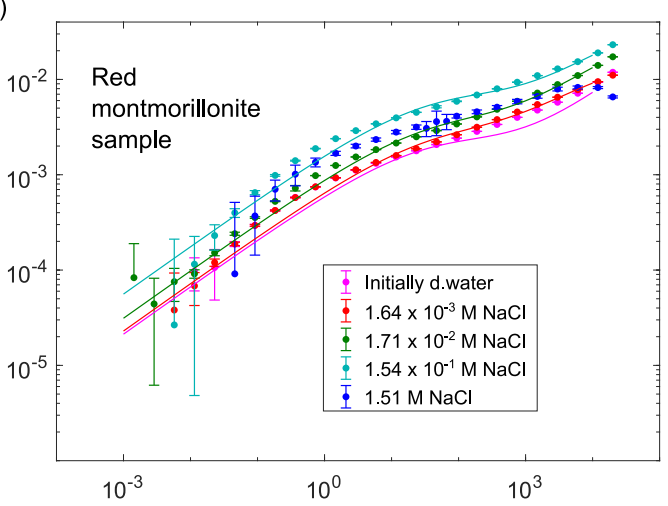

d)

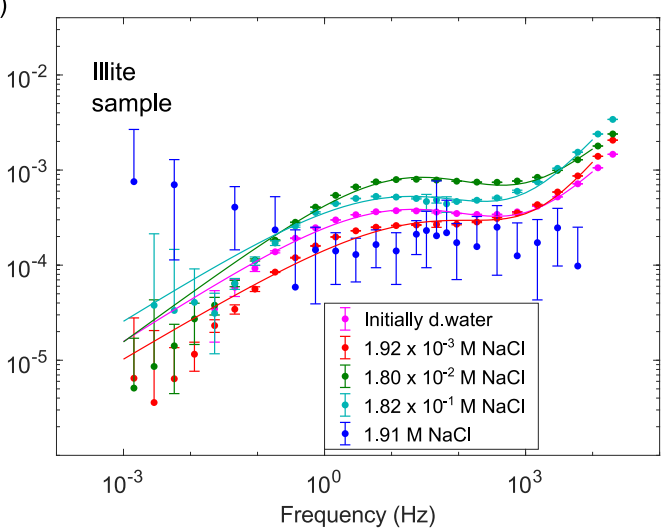

Figure 7. Imaginary part of the complex conductivity per salinity of: a) green montmorillonite sample, b) red montmorillonite sample, c) kaolinite sample, and d) illite sample. The calculated salinity values at which the SIP measurements were collected are presented in the legends of each subplot. Dots with errorbars represent the measured SIP data, and the line represents the double-Pelton model predictions for each dataset. 
between the injected current and the resulting measured voltage signal, is a real challenge for the electronics involved in SIP measurements (Zimmermann et al., 2008). Nevertheless, it is possible to distinguish a clear tendency with frequency, in most of the spectra, except for the illite and kaolinite samples at the highest salinity.

\subsection{Double-Pelton model fits and variation of Pelton parameters with varying salinities}

In Figure 8 we present the principle of the double-Pelton model decomposition. We sum two individual Pelton signals (see equation 6), the resulting signal is the one that we fit our data with. Note that we ran more than 3 simulated annealing optimizations to check for the repeatability of the solution and in all cases we found the same solution. It is also worth mentioning that we use filtered data for this process, for which the errorbars are negligible. We assume that the high frequency peak (in blue) happens due to partly an inductive and capacitive effect (Huisman et al., 2016) plus polarization of the clay (Leroy \& Revil, 2009; Okay et al., 2014; Leroy et al., 2017a). We assume that the mid-frequency peak (in red) corresponds solely to the polarization of clay.

In Table 4 we have summarized the optimized Pelton parameters of both the red and blue peaks (Figure 8). Furthermore, as mentioned previously, we used a double-Warburg model $\left(c_{1}=0.5\right.$ and $\left.c_{2}=0.5\right)$ for all clay samples except the illite sample, that was fitted with a double-Pelton (fitted $c_{1}$ and $c_{2}$ ). We present fully the double-Pelton parameters as we believe it will be of interest to the community to have access to Pelton parameters of individual types of clays at varying salinities, for possible forward-modeling opportunities.

For the four lowest salinity datasets, we observe how at the highest fitted salinity, there is a considerable decrease in the chargeability $\left(\mathrm{m}_{1}\right)$ parameter for the lower frequency local maxima. For all datasets we see chargeability values (in each individual local maxima) in the same magnitude order. We also see an increase on DC electrical conductivity with increasing salinity, as expected. Note that we present values of electrical conductivity, instead of resistivity (as shown in the double-Pelton model, equation 6), as the complex conductivity is only the inverse to the complex resistivity. As for the illite sample, we see that for $c_{1}$ all values linger near 0.5 , but not quite 0.5 . Finally, we see that 
Table 4. Double-Pelton parameters obtained from the optimization procedure of section 3.4 to reproduce SIP signal on the four studied clay types.

\begin{tabular}{|c|c|c|c|c|c|c|c|c|c|}
\hline Clay type & Salinity $[\mathrm{M} \mathrm{NaCl}]$ & $\sigma_{0}\left[\mathrm{~S} \mathrm{~m}^{-1}\right]$ & $m_{1}[\mathrm{mV} / \mathrm{V}]$ & $\tau_{1}[\mu \mathrm{s}]$ & $\mathrm{c}_{1}$ & $m_{2}[\mathrm{mV} / \mathrm{V}]$ & $\tau_{2}[\mu \mathrm{s}]$ & $\mathrm{c}_{2}$ & RMS [-] \\
\hline \multirow{2}{*}{ Kaolinite } & D.W. & 0.074 & 40.14 & 333 & 0.5 & 345 & 0.327 & 0.5 & $1.78 \times 10^{-3}$ \\
\hline & $1.53 \times 10^{-3}$ & 0.089 & 40.68 & 332 & 0.5 & 249 & 0.599 & 0.5 & $1.82 \times 10^{-3}$ \\
\hline \multirow{2}{*}{ sample } & $1.54 \times 10^{-2}$ & 0.146 & 34.86 & 413 & 0.5 & 142 & 1.483 & 0.5 & $1.52 \times 10^{-3}$ \\
\hline & $1.91 \times 10^{-1}$ & 0.797 & 5.66 & 842 & 0.5 & 350 & 0.014 & 0.5 & $2.63 \times 10^{-2}$ \\
\hline \multirow{2}{*}{ Illite } & D.W. & 0.057 & 34.26 & 10110 & 0.45 & 682 & 0.063 & 0.66 & $4.82 \times 10^{-3}$ \\
\hline & $1.92 \times 10^{-3}$ & 0.080 & 20.00 & 3261 & 0.42 & 740 & 0.143 & 0.84 & $5.26 \times 10^{-3}$ \\
\hline \multirow{2}{*}{ sample } & $1.80 \times 10^{-2}$ & 0.159 & 22.57 & 7662 & 0.51 & 515 & 0.021 & 0.56 & $6.18 \times 10^{-3}$ \\
\hline & $1.82 \times 10^{-1}$ & 0.557 & 5.11 & 10369 & 0.44 & 342 & 0.043 & 0.76 & $7.21 \times 10^{-3}$ \\
\hline \multirow{2}{*}{ Green mont. } & D.W. & 0.213 & 37.40 & 4418 & 0.5 & 158 & 1.917 & 0.5 & $4.75 \times 10^{-3}$ \\
\hline & $1.39 \times 10^{-3}$ & 0.257 & 32.55 & 3432 & 0.5 & 249 & 0.56 & 0.5 & $4.23 \times 10^{-3}$ \\
\hline \multirow{2}{*}{ sample } & $1.53 \times 10^{-2}$ & 0.347 & 28.27 & 3957 & 0.5 & 198 & 0.803 & 0.5 & $2.72 \times 10^{-3}$ \\
\hline & $1.46 \times 10^{-1}$ & 0.877 & 18.48 & 5758 & 0.5 & 504 & 0.052 & 0.5 & $3.87 \times 10^{-3}$ \\
\hline \multirow{2}{*}{ Red mont. } & D.W. & 0.171 & 42.32 & 2266 & 0.5 & 958 & 0.048 & 0.5 & $9.61 \times 10^{-2}$ \\
\hline & $1.64 \times 10^{-3}$ & 0.245 & 30.87 & 2046 & 0.5 & 200 & 1.88 & 0.5 & $3.78 \times 10^{-3}$ \\
\hline \multirow{2}{*}{ sample } & $1.71 \times 10^{-2}$ & 0.387 & 27.47 & 2033 & 0.5 & 306 & 0.452 & 0.5 & $3.85 \times 10^{-3}$ \\
\hline & $1.54 \times 10^{-1}$ & 0.805 & 25.76 & 1846 & 0.5 & 188 & 0.528 & 0.5 & $7.41 \times 10^{-3}$ \\
\hline
\end{tabular}

the relaxation times for the second (high frequency) local maxima are mostly below the $\mu \mathrm{s}$ range, and that for the second local maxima, these are considerably above.

\subsection{Differentiation of clay minerals}

After calculating the $\Delta \sigma_{N}^{\prime}$ and $\Delta \sigma_{N}^{\prime \prime}$ values (equation 9), we see that the values $\Delta \sigma_{N}^{\prime}$ decrease with increasing salinities overall, agreeing with what we observe in Figure 5, for the normalized real conductivity. This behavior is not so clear or evident for the imaginary part. We also observe that the $\Delta \sigma_{N}^{\prime}$ and $\Delta \sigma_{N}^{\prime \prime}$ values are smaller between the montmorillonite samples, as expected, that is the montmorillonite samples are electrically similar to each other. For the lowest salinity (initially de-ionized water) the biggest difference in real conductivity is between the illite and the green montmorillonite samples $(-116 \%$, the real conductivity of the illite sample is smaller than that of the montmorillonite sample), and for the imaginary part it is between the kaolinite and the green montmorillonite samples $(-149 \%$, the imaginary conductivity of the kaolinite sample is smaller than that of the montmorillonite sample). For the initial $10^{-3} \mathrm{M}$ salinity $(\mathrm{NaCl})$ the biggest difference in real conductivity is between the illite and the green montmorillonite samples 
a)

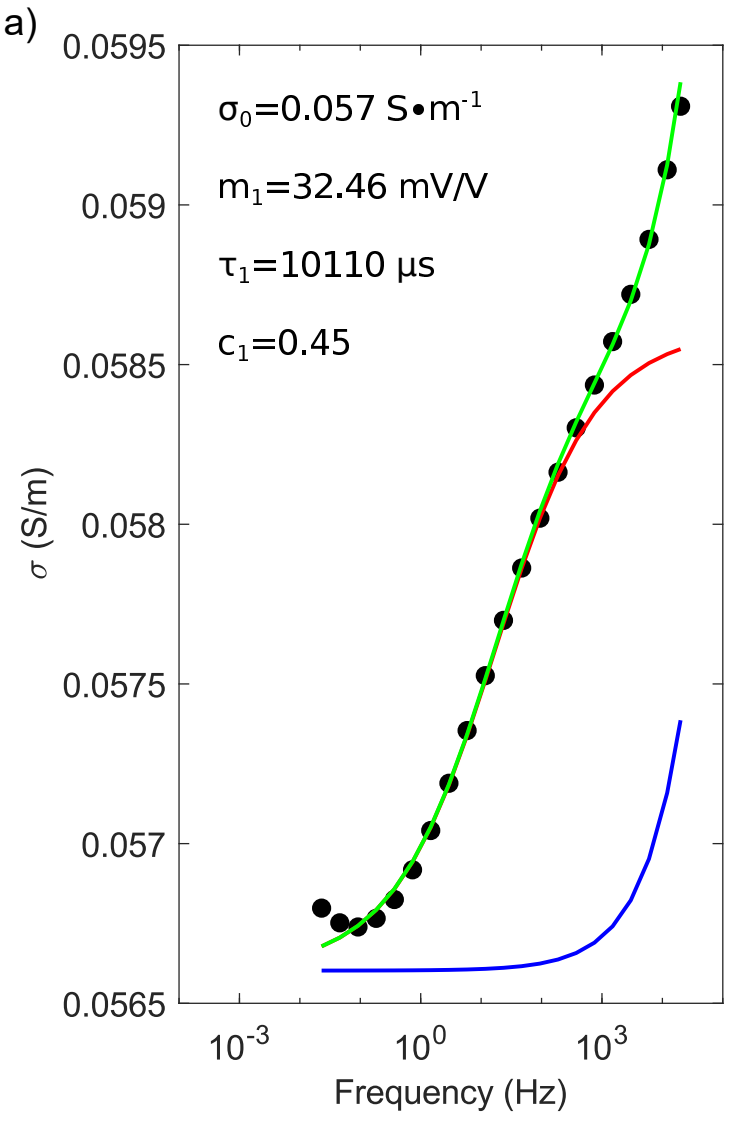

b)

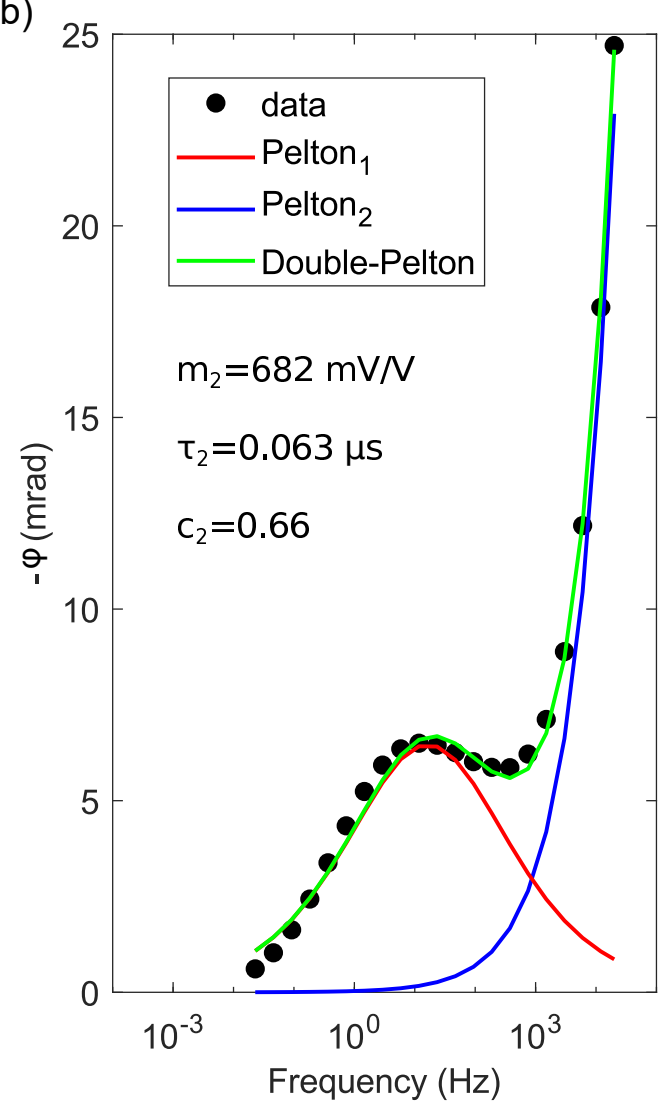

Figure 8. Fit of a double-Pelton model (equation 6) to our data, in both a) amplitude and b) phase. We present the illite sample dataset using initial de-ionized water (filled circles), and the corresponding double-Pelton model (green line), with two individual Pelton models (blue and red lines). 
Table 5. $\Delta \sigma_{N}^{\prime}$ and $\Delta \sigma_{N}^{\prime \prime}$ values (in $\%$ ) for the initially $10^{-2} \mathrm{M}$ of $\mathrm{NaCl}$ clay mixtures. These calculations are made using the complex conductivity at $1.46 \mathrm{~Hz}$, the real part $\left(\Delta \sigma_{N}^{\prime}\right)$ is on the lower left triangle (in bold), and the imaginary part $\left(\Delta \sigma_{N}^{\prime \prime}\right)$ is on the upper right triangle (in italics). MtG represents the green montmorillonite sample, MtR the red montmorillonite sample, Ka the kaolinite sample, and IL the illite sample.

\begin{tabular}{c|cccc}
\hline & $\mathrm{MtG}$ & $\mathrm{MtR}$ & $\mathrm{Ka}$ & $\mathrm{IL}$ \\
\hline $\mathrm{MtG}$ & 0 & 2.56 & 129.84 & 81.20 \\
$\mathrm{MtR}$ & $\mathbf{1 0 . 8 5}$ & 0 & 128.34 & 79.06 \\
$\mathrm{Ka}$ & $\mathbf{- 8 2 . 0 0}$ & $\mathbf{- 9 0 . 8 3}$ & 0 & -66.04 \\
$\mathrm{IL}$ & $\mathbf{- 7 4 . 3 7}$ & $\mathbf{- 8 5 . 5 3}$ & $\mathbf{9 . 0 1}$ & 0 \\
\hline
\end{tabular}

$(-105 \%)$, and for the imaginary part it is between the kaolinite and the green montmorillonite samples $(-143 \%)$. For the initial $10^{-2} \mathrm{M}$ salinity, the biggest difference in real conductivity is between the kaolinite and the red montmorillonite samples $(-91 \%)$, and for the imaginary part it is between the kaolinite and the green montmorillonite samples $(-130 \%)$. For the initial $10^{-1} \mathrm{M}$ salinity, the biggest difference in real conductivity is between the illite and the green montmorillonite samples $(-45 \%)$, and for the imaginary part it is between the kaolinite and the green montmorillonite samples $(-162 \%)$. For the highest salinity, the biggest difference in real conductivity is between the kaolinite and the green montmorillonite samples (20\%), and for the imaginary part it is between the kaolinite and the red montmorillonite samples $(-169 \%)$. Table 5 presents the $\Delta \sigma_{N}^{\prime}$ and $\Delta \sigma_{N}^{\prime \prime}$ values for the initial salinity of $10^{-2} \mathrm{M}$ of $\mathrm{NaCl}$. We use $x_{1}$ (see equation 9) as the value of the column, and $x_{2}$ of the row. For example, in Table 5, we obtained 10.85, using the $\sigma^{\prime}$ of the red montmorillonite sample as $\sigma_{1}^{\prime}$, and of the green montmorillonite sample as $\sigma_{2}^{\prime}$ (see equation 9). The lower left triangle corresponds to calculation for the real part $\left(\Delta \sigma_{N}^{\prime}\right)$ of the complex conductivity (in bold), and the upper right triangle corresponds to the imaginary part $\left(\Delta \sigma_{N}^{\prime \prime}\right.$, in italics). The tables for the rest of the salinities are presented in the supplementary information part of this paper. 


\section{Discussion}

In this study we propose a new experimental protocol with verified repeatability to characterize the complex electrical conductivity spectra of non-consolidated clay samples. We obtain a unique SIP dataset composed of four types of clay samples and saturated by a $\mathrm{NaCl}$ solution at five different salinities. We first interpreted the dataset at $1.46 \mathrm{~Hz}$ for the real and imaginary parts of the electrical conductivity before studying the entire spectra and fitting them with a double-Pelton phenomenological model, and presenting a schematic figure on how we interpret the polarization phenomena of our results.

Our measurements, at $1.46 \mathrm{~Hz}$ (Figure 4b), show that the quadrature conductivity (imaginary part of the complex conductivity) hits a maximum at a certain salinity and then decreases. The salinity at which this maximum exists depends on the type of clay. For the kaolinite and the illite samples, we have the maximum at the mid-salinity (around $10^{-2} \mathrm{M}$ of $\mathrm{NaCl}$ salinity range), while it is a higher salinity for the montmorillonite samples (around $10^{-1} \mathrm{M}$ of $\mathrm{NaCl}$ ). It should be noted that we do not have the exact salinity at which the maximum quadrature conductivity happens because we investigated 5 finite salinities, that is, perhaps the maximum of the quadrature happens between two of our measured salinities. Among the published SIP datasets on clay samples, Vinegar \& Waxman (1984) present an extensive dataset of the complex electrical conductivity from 21 shaly sands, measured at 4,5 or 7 different salinities $(0.01,0.05,0.1,0.25,0.5$, 1.0, and $2.0 \mathrm{M} \mathrm{NaCl}$ ); see Tables 1 and 2 of Vinegar \& Waxman (1984). Some of their samples also exhibit the behavior with a maximum quadrature conductivity at a particular salinity, notably the samples with more shale content. They propose that the decrease of the quadrature conductivity happens due to a decrease of the membrane effect. Weller et al. (2010) proposed that the relationship between the imaginary conductivity and the water conductivity is guided by the specific surface area per unit pore volume. For this, they analyzed IP or SIP data from 114 samples, including sandstones, and sand and clay mixtures. Revil \& Skold (2011) also present a dataset composed of 7 samples of sandstones and unconsolidated sand from the literature where most of the datasets present the same trend where a maximum in quadrature conductivity appears at a particular salinity. The behavior shown in Figure $4 \mathrm{~b}$ is also consistent with the one reported by Weller \& Slater (2012), both share the same water conductivity range. They measured SIP on 67 samples of sandstones and unconsolidated sediments. Okay et al. (2014) 
measured SIP on bentonite and kaolinite quartz sand mixtures, at different clay contents $100 \%, 20 \%, 5 \%$, and $1 \%$. They present the behavior of the quadrature conductivity with respect to water conductivity at only three $\mathrm{NaCl}$ salinities. Their bentonite samples $(95 \%$ smectite content) and kaolinite samples (15\% smectite content) present an increase in the quadrature conductivity with salinity; the maximum water conductivity presented is around $1.5 \mathrm{~S} / \mathrm{m}$. Finally, Lévy et al. (2019b) measured the SIP response of a set of 88 volcanic altered rocks with varying amounts of smectite. They present the SIP spectra from four of their samples (Figure 1 in Lévy et al., 2019b), using four different fluid conductivities, $0.04,0.1,0.5$, and $1.5 \mathrm{~S} \mathrm{~m}^{-1}$ (from four different $\mathrm{NaCl}$ concentrations). They show an overall increase in polarization (quadrature conductivity) with salinity for these four samples. If we only analyze the smectite samples of our dataset, we see a progressive increase in the quadrature conductivity with increase of fluid conductivity, until we reach the highest salinity, where we see a decrease (see Figure $4 \mathrm{~b}$ ). Only one of the samples presented with the full conductivity spectra (Figure 1 in Lévy et al., 2019b) has more than $20 \%$ smectite. If we only take a look at this sample, it doesn't show a decrease in quadrature conductivity with the highest salinity, although, their highest presented pore water conductivity for this data subset is $1.5 \mathrm{~S} \mathrm{~m}^{-1}$. For the smectite samples of our dataset, we see a decrease on the quadrature conductivity just at the highest pore water conductivity, around $10 \mathrm{~S} \mathrm{~m}^{-1}$. According to these studies, it is interesting to notice that the increase of the quadrature conductivity with salinity is larger for sandstones and quartz sand than for smectite minerals. This observation confirms the assumption that the quadrature conductivity of these materials is directly sensitive to their surface charge controlling EDL polarization (Okay et al., 2014; Leroy et al., 2017a). Indeed, the surface charge of quartz strongly increases with $\mathrm{pH}$ and salinity due to the deprotonated silanol surface sites whereas the smectite minerals carry a permanent negative surface charge less sensitive to $\mathrm{pH}$ and salinity on their basal surface due to isomorphic substitutions in the crystal lattice. Weller \& Slater (2012) suggest further investigation at even higher salinities, this could be important for high salinity environments, such as oceanic shale reservoirs (Morsy \& Sheng, 2014). Due to such a high electrical conductivity of such sample, the SIP measurement logistics could be complex, and better protocols and measuring equipment with low uncertainty at high conductivities are needed. 
Furthermore, Weller et al. (2013), Woodruff et al. (2014), and Lévy et al. (2019b) observed a linear relation between $\sigma_{\text {surf }}^{\prime \prime}$ and $\sigma_{\text {surf }}^{\prime}$. Weller et al. (2013) used a database composed of 63 sandstones and unconsolidated sediment samples. They overall found the linear parameter $(l)$ of equation 5 to be 0.042 . Woodruff et al. (2014) worked on a variety of shales, and found $l=0.022$ for their dataset, they call it parameter $\mathrm{R}$ in their work. In addition, Lévy et al. (2019b) studied a variety of volcanic rocks, with different smectite contents, and they found that the linear relation between $\sigma_{\text {surf }}^{\prime \prime}$ and $\sigma_{\text {surf }}^{\prime}$ decreases in magnitude with smectite content. They calculate $l=0.002$ for a data subset with more than $20 \%$ smectite content. According to Revil (2012), this very low $l$ value of samples with high smectite content compared to the $l$ value of sandstones and unconsolidated sediment samples may be due to the restricted cation mobility in the Stern layer of clays. Also, it is not sure that it is possible to correctly capture the surface conductivity of clays with such linear model (de Lima \& Sharma, 1990).

We used $\sigma^{\prime}$ values at $1.46 \mathrm{~Hz}$ for the four highest salinities $\left(10^{-3}-1 \mathrm{M}\right.$ of $\left.\mathrm{NaCl}\right)$ to adjust one formation factor and one surface conductivity per clay type using equation 2 . Then, we recalculated $\sigma_{\text {surf }}^{\prime}$ values for each salinity (using equation 3) and considered equation 4 to associate the measured values of $\sigma^{\prime \prime}$ to $\sigma_{\text {surf }}^{\prime \prime}$. Figure $9 \mathrm{~b}$ shows the relation between $\sigma_{\text {surf }}^{\prime}$ and $\sigma^{\prime \prime}$. We obtained the best fit for equation 5 for $l=0.0039$, that is, almost an order of magnitude smaller than the value of Weller et al. $(2013)(l=0.042)$ from samples containing no clay. Our data agree more with the value of $l$ proposed by Lévy et al. $(2019 b)(l=0.002$, when samples had more than $20 \%$ smectite), than the one of Weller et al. (2013). As we only consider clay samples, this difference could be attributed to the difference in mineralogical composition. Perhaps sandstones and sediments behave more like what Weller et al. (2013) present, but as clay materials have a significant $\sigma_{\text {surf }}^{\prime}$, they present a different, but also seemingly linear behavior.

In order to test the hypothesis that $l$ decreases with clay content, in Figure 9a we evaluated the combined dataset of Woodruff et al. (2014), Lévy et al. (2019b), and ours. For Lévy et al. (2019b) we selected the data that contained more than $20 \%$ smectite, from their Table 1 . As mentioned previously, using only our dataset we obtain $l=0.0039$. From Figure 9a we can see that none of the proposed values for $l$ fit perfectly this combined dataset. The results are in agreement with Lévy et al. (2019b) on the idea that $l$ seems to decrease with increasing smectite content. Further than that, these data would seem to suggest that the relation between $\sigma^{\prime \prime}$ and $\sigma_{\text {surf }}^{\prime}$ is a non-linear one over multi- 
ple types of minerals. A more thorough analysis over multiple types of minerals needs to be performed in order to determine if there is a larger obtainable linear or non-linear relation between $\sigma^{\prime \prime}$ and $\sigma_{\text {surf }}^{\prime}$. Another interesting relationship that is studied between two SIP parameters is the relationship between $\sigma^{\prime \prime}$ and the surface area per unit volume $\left(\mathrm{S}_{\text {por }}\right)$, see Weller et al. (2015a) and Revil (2012). In the supplementary information, we present a comparison of our data and that presented in Weller et al. (2015a) and Börner (1992). It should be noted that we use clay samples and not a mix of sand and clay, and thus the results between the data presented in Weller et al. (2015a), Börner (1992), and our data do not align perfectly. As a whole, we observe that the imaginary conductivity increases with the surface area per unit volume, as previously observed by Börner (1992), Revil (2012), and Weller et al. (2015a).

Among the various existing phenomenological models, we used a double-Pelton model to fit our data. We noticed that a double-Warburg model $(\mathrm{c}=0.5)$ was suitable for three of our datasets (kaolinite, red, and green montmorillonite samples). Revil et al. (2014) have proposed rather the use of a Warburg model over a Debye or Pelton model, after analyzing SIP datasets of metal-free and clayey materials. This holds true for three of the measured types of clay, that is the kaolinite, red and green montmorillonite samples. Only the illite sample cannot be fitted by a double-Warburg and presents the most noticeable mid-frequency (around $10 \mathrm{~Hz}$ ) peak of all the measured types of clay. We present in Figure 10, trends we found among all double-Pelton parameters. To further interpret the results of the double-Pelton model, one can consider the classic formula of chargeability $(m)$ :

$$
m=\frac{\sigma_{\infty}-\sigma_{0}}{\sigma_{\infty}},
$$

where $\sigma_{\infty}$ can be thought of as the conductivity at high frequency or the AC conductivity due to polarization plus the DC conductivity, and $\sigma_{0}$ can be thought of as the conductivity at low frequency or only the DC conductivity. In this way, if we notice an increase of $m_{1}$ or $m_{2}$, we could interpret this as that possibly AC conductivity increases faster with respect to DC conductivity. Similarly, if we notice a decrease of $m_{1}$ or $m_{2}$, we could interpret this as DC conductivity increasing faster than the AC conductivity. We see an overall decrease of $m_{1}$ with an increase of $\sigma_{0}$, and we observe a decrease of $\tau_{2}$ with an increase of $m_{2}$. We could interpret the first as a direct result of our data pro- 


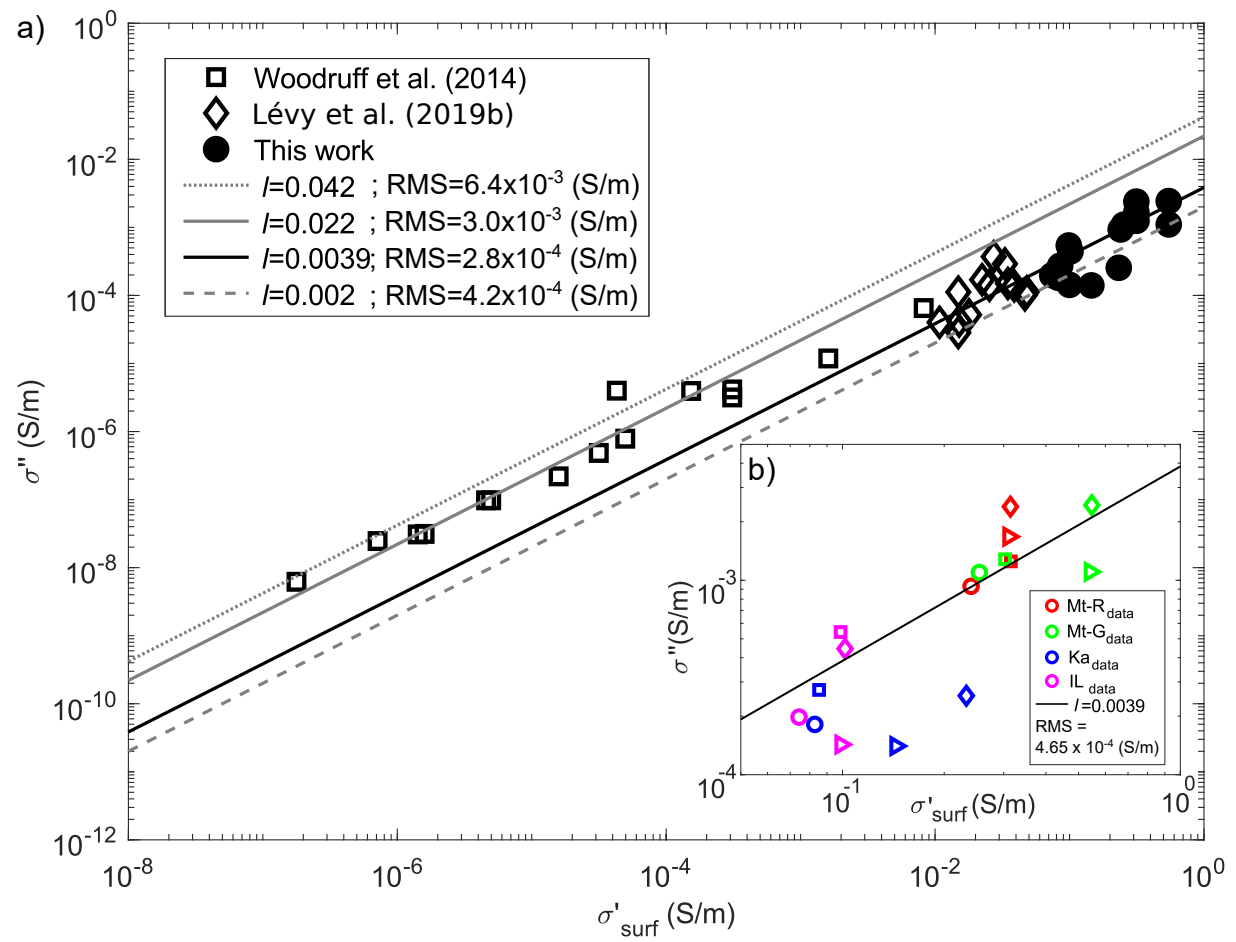

Figure 9. Relationship between $\sigma^{\prime \prime}$ and $\sigma_{\text {surf }}^{\prime}$. a) Comparison of different linear parameters presented in the literature and the datasets from Woodruff et al. (2014) and Lévy et al. (2019b). b) Linear fit $(l=0.0039)$ between $\sigma^{\prime \prime}$ and $\sigma_{\text {surf }}^{\prime}$, with our data at $1.46 \mathrm{~Hz}$ and with the four highest salinities. The red symbols represent the red montmorillonite sample, the green represent the green montmorillonite sample, the blue symbols the kaolinite sample, and the magenta represent the illite sample. The symbols (in b) representing data from the lower to higher salinity are: circle, square, diamond, and triangle. 
cessing protocol. By optimizing the Pelton parameters from the curves of amplitude and phase, we see an overall decrease of the mid-frequency peak (red peak in Figure 8b) with an increase in salinity of the clay sample. We attribute the decrease of $m_{1}$ with salinity to maybe the cease of a polarization mechanism at a particular salinity. The fact that we don't necessarily see a decrease of $m_{2}$ with salinity means that perhaps, at a certain salinity some other polarization mechanisms are still active. Which polarization mechanism acts at which salinity is still an open question. Further investigation needs to be done, specifically on the modeling side, to better understand the SIP response of clay samples for varying salinities, with individual polarization mechanisms in mind. The correlation of $\tau_{2}$ and $m_{2}$ could be an artifact present in our optimization process. However, we do not see such a behavior between $\tau_{1}$ and $m_{1}$. Schwartz \& Furman (2015) adjust a single Pelton on their SIP data on soil organic matter, and they also see a decrease of $\tau$ with an increase of $m$. They attribute this phenomenon to the fact that an ion mobility reduction causes an increase in the relaxation time and a decrease in polarization. Indeed, as presented in Table 4 and Figure 10b, we see that for $m_{2}$ and $\tau_{2}$ of our dataset this holds truth as well. An explanation of the observed inverse correlation between $m_{2}$ and $\tau_{2}$ could be also due to the EDL polarization of the smallest clay particles at high frequency. Large clay particles tend to polarize less than smaller clay particles due to their lower total specific surface area, and thus lower surface conductivity. However, the relaxation time of the EDL polarization increases when the size of the particle increases. Therefore, the chargeability due to these small clay particles may decrease when the relaxation time increases. More modeling work is necessary on the polarization of the EDL of clay particles to better interpret our results with respect to individual polarization mechanisms, in particular the EDL polarization.

Our $\Delta \sigma_{N}^{\prime}$ and $\Delta \sigma_{N}^{\prime \prime}$ calculations agree with the fact that the highest conduction and polarization values come from the smectite samples. We could interpret this as a result of the fact that the smectite samples have a higher specific surface area than illite sample, which has a higher specific surface area than the kaolinite sample. The surface charge of montmorillonite and illite may also be higher in magnitude than the surface charge of kaolinite. The imaginary conductivity amplitude is roughly one order of magnitude higher for the montmorillonite samples than for other clay samples. Due to their higher specific surface area and stronger EDL (reflected in the CEC measurements, see Table 3), the montmorillonite samples may polarize more than the kaolinite and illite samples, 
a)

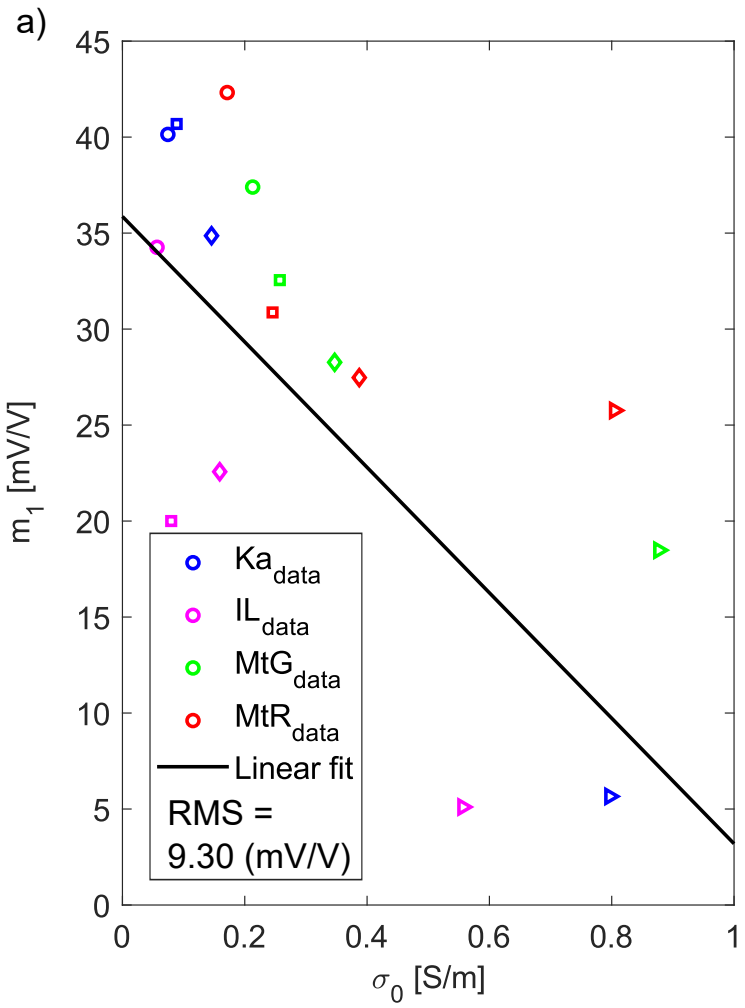

b)

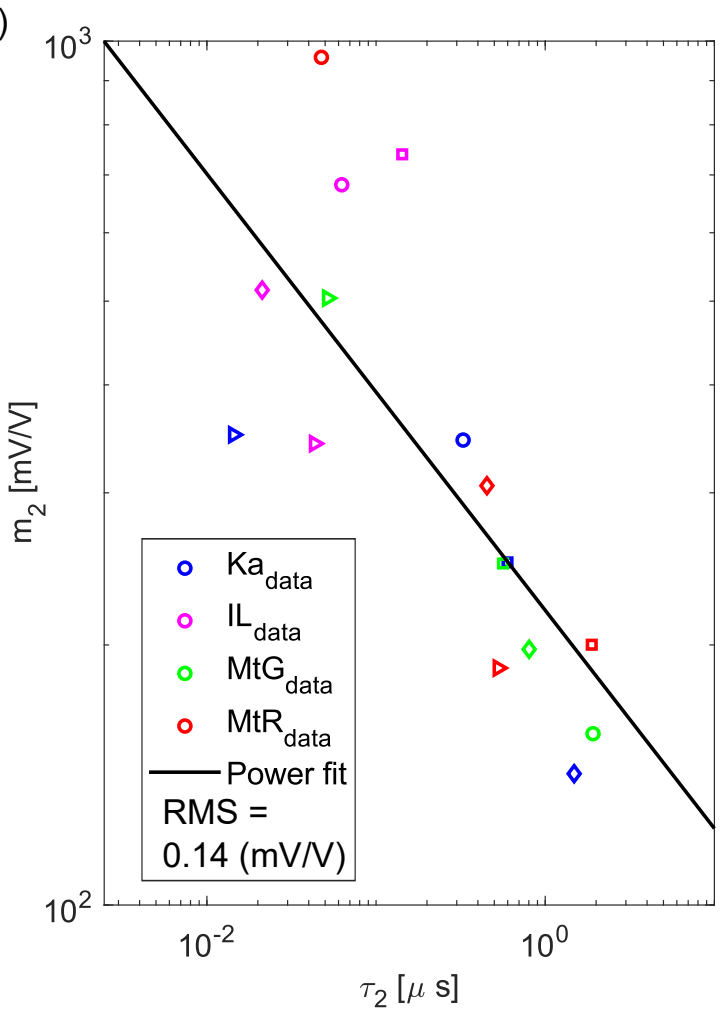

Figure 10. From the double-Pelton optimization parameters: a) dependence of $m_{1}$ and $\sigma_{0}$, and b) dependence of $\tau_{2}$ and $m_{2}$. The red symbols represent the red montmorillonite sample, the green represent green montmorillonite sample, the blue the kaolinite sample, and the magenta represent the illite sample. The symbols representing data from lower to higher salinity are: circle, square, diamond, and triangle. 
and this may also explain why more salt is necessary to "saturate" the EDL polarization controlling imaginary conductivity. For the red and green montmorillonite samples, we interpret the fact that the peak of polarization (see Figure 4) happens around a $10^{-1}$ $\mathrm{M} \mathrm{NaCl}$ salinity due to the high electrical charge (see the CEC values in Table 3 ) on the basal surfaces of all smectites. Diffuse layers around montmorillonite particles are strongly repulsive, meaning that a high ion concentration in the pore water is necessary to compress the diffuse layers which decreases membrane polarization effects and favour coagulation of the particles (Tombácz \& Szekeres, 2006). Coagulated particles exhibit a smaller external surface area available for polarization. Illite and kaolinite have a smaller specific surface area, therefore, the peak in their imaginary conductivity may happen at a smaller ion concentration in the pore water.

If we take a look at Figures 6 and 7, we see that for both conductivities (real and imaginary), the montmorillonite samples are less dispersed than the kaolinite and illite samples. Meaning, the maximum and minimum values are closer together for the montmorillonite samples than for the illite and kaolinite samples. This could be due to the fact that montmorillonites have a far more important specific surface area than illite and kaolinite, therefore a change in salinity effects more the conductivities (real and imaginary) of kaolinite and illite. Furthermore, we can observe in Figure 6 that the surface conductivity of the montmorillonite samples is higher than the surface conductivity of the kaolinite and illite samples. We can see this as in the lowest salinity, we have higher values for the real conductivity of the montmorillonite samples in comparison to the kaolinite and illite samples. At the lowest salinity, we can assume that the surface conductivity is the most important between pore water conductivity and surface conductivity (see equation 2). The high surface conductivity of the montmorillonite samples could also explain the fact that the difference between maximum and minimum conductivities is bigger for the kaolinite and illite samples, than for the montmorillonite samples (see Figure 6). Again, as the salinity increases (more available ions), it can significantly effect the pore water conductivity and thus the total measured conductivity of the kaolinite and illite samples. As for the montmorillonite samples, this is less clear because of the high surface conductivity. For the montmorillonites and kaolinite samples, the imaginary conductivity spectra are less sensitive to salinity than for the illite sample. This may be due to the permanent negative surface charge of the basal surface of montmorillonite (see Figure 1) which may control polarization of montmorillonites and kaolinite (to a lesser ex- 
tent due to a significant content of smectite). In addition, the illite sample exhibits a polarization peak at a frequency of around $10 \mathrm{~Hz}$, which is not seen for the other clay types (flatter signals). Following Schwarz (1962), we could attribute this $10 \mathrm{~Hz}$ peak of polarization in the illite sample to a possible presence of bigger clay aggregates compared to the rest of the clay samples. The illite sample used for our measurements (see Table 1) has $12 \%$ calcite that could perhaps correspond to polarization around large calcite grains, or a smaller polarization of grains themselves, as shown by Leroy et al. (2017b).

In Figure 11 we present a conceptual sketch of what we interpret occurs to clay particles with increasing salinity. As the salinity increases, it seems plausible that clay particles coagulate; and thus the distance between clay particles decreases with increasing salinity, up until a point of coagulation where two clay particles can be thought of as a thicker clay particle. As a result, initially at the lowest salinity (Figure 11a), we have two clay particles with a negative surface charge, and an overlapping diffuse layer, with a membrane effect polarization. At the mid-salinity (Figure 11b), we have a larger ionic concentration $(\mathrm{NaCl})$, thus more available ions to polarize, and so we see an increase in polarization from Figure 11a to Figure 11b. However, we see an overlap in the diffuse layer, with a possible reduced membrane effect polarization. Therefore the overall total polarization increases from Figure 11a to Figure 11b (even if individual polarization mechanisms such as the membrane polarization decreases from Figure 11a to Figure 11b). On the contrary, at the highest salinity (Figure 11c), where clay particles have coagulated and thus we have a smaller external specific surface charge; a smaller area for ions to polarize. In addition, we have a null membrane polarization effect at the highest salinity. To make the link with Figure 4b, for the montmorillonite samples, the two lowest salinities $\left(10^{-2}-10^{-1} \mathrm{~S} / \mathrm{m}\right.$ range) would correspond to the state presented in Figure 11a, the $10^{0} \mathrm{~S} / \mathrm{m}$ salinity would correspond to in Figure $11 \mathrm{~b}$, and the $10^{1} \mathrm{~S} / \mathrm{m}$ would correspond to Figure 11c. For the kaolinite and illite samples, we would rather couple the $10^{-2} \mathrm{~S} / \mathrm{m}$ (presented in Figure $4 \mathrm{~b}$ ) to Figure 11a, the $10^{-1} \mathrm{~S} / \mathrm{m}$ to Figure $11 \mathrm{~b}$, and finally the two highest salinities $\left(10^{0}-10^{1} \mathrm{~S} / \mathrm{m}\right.$ range $)$ to $11 \mathrm{c}$. This is consistent with, Vinegar \& Waxman (1984), who proposed that the decrease of the quadrature conductivity with salinity in shaly sands happens due to a decrease of the membrane effect. Revil (2012) mentions that there is a relative change on the effect of polarization mechanisms with salinity. Furthermore, Hördt et al. (2016) made a numerical membrane polarization study of wide and narrow pores of different sizes and varying salinity and $\mathrm{pH}$. They find that 
$\mathbf{E}$

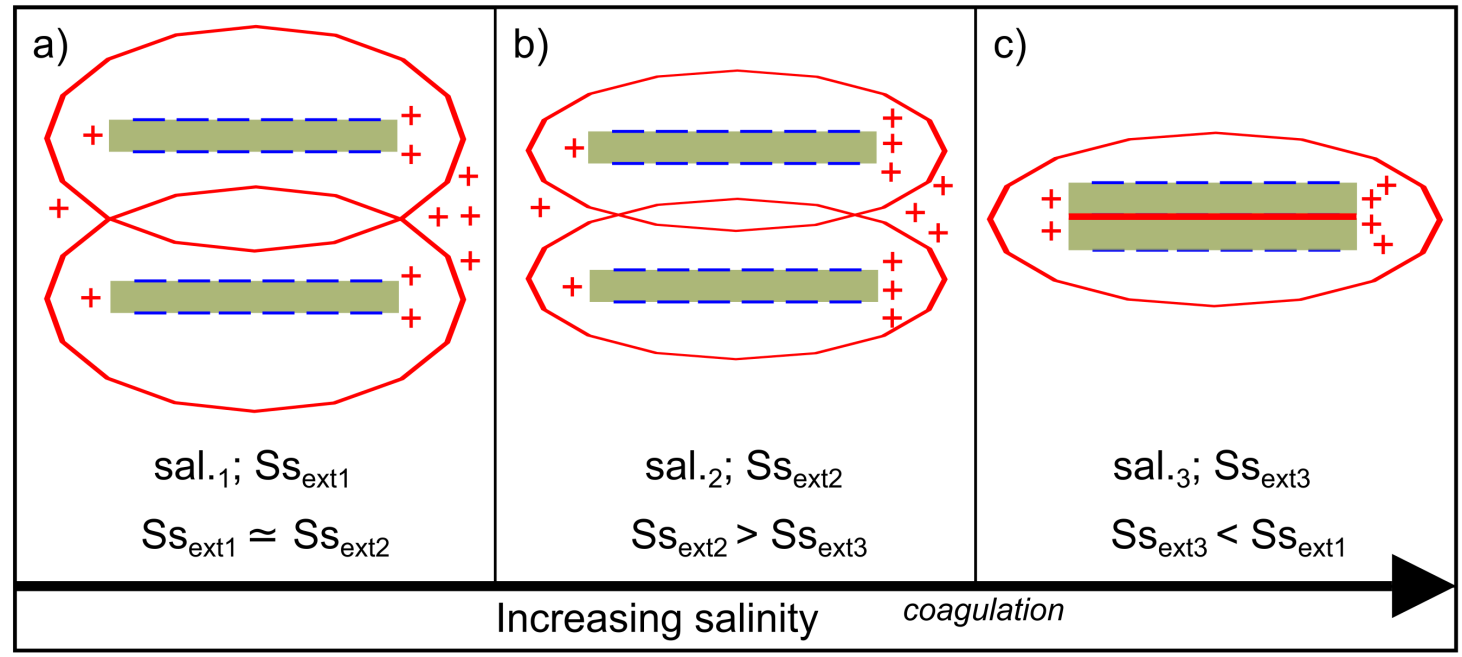

Figure 11. An interpreted process of how clay particles behave with increasing salinity. The state of two clay particles at a) the lowest salinity, b) mid-salinity and c) highest salinity. In green we present individual clay particles. In blue the negative surface charge of the clay particle, and in red the EDL (Stern and diffuse layer). In this figure, we refer as sal. to salinity, and $S s_{\text {ext }}$ to the specific surface area of the clay particle. Numbers 1, 2, and 3 represent different stages of increasing salinity and therefore coagulation.

specially for narrow pores, the imaginary conductivity increases with salinity until a maximum value, and then decreases. Additionally, Weller et al. (2015b) and Lesmes \& Frye (2001) have interpreted the decrease of the polarization of sandstones at high salinities by a decrease of the ionic mobility at high salinities in the EDL. Although according to molecular dynamics (MD) predictions (Bourg \& Sposito, 2011), the mobility of counterions $\left(\mathrm{Na}^{+}\right)$in the Stern layer does not decrease when salinity increases. More physical or numerical modeling of clays needs to be done to better understand exactly how each phenomenon (clay coagulation and decrease of ionic mobility) effects the polarization of clay samples at varying salinities.

On the differentiation of clay types by using SIP, we can think of two things. If we take a look at the parameters of Table 4, we could say these parameters are very close to each other, and on a field scale experiment, realistically differentiating two types of clay seems very ambitious. The success of such a task would depend on the fieldwork planning, so 
a correct resolution is used, but with single parameters such as $\sigma_{0}$, the task would seem complicated. However, if we take a look at figures 6 and 7, differentiating types of clay using multiple frequencies seems easier of a task. Therefore, if a fieldwork campaign is carried out with the objective of differentiating two or more types of clay in a formation, we recommend using multi-frequency electrical methods. Moreover, differentiating two types of montmorillonites in the field and laboratory scale seems impossible if only using geo-electrical methods. However, differentiating between a montmorillonite and illite or kaolinite seems more achievable of a task in both the field and laboratory scales. If in the laboratory we run experiments in a controlled environment using relatively pure clays, the application of our findings in the field will be more challenging due to a combination of subsurface heterogeneity and greater measurement noise due to larger coupling effects.

Zonge et al. (2005) mention that the differentiation of clay types in IP is possible at frequencies above $1000 \mathrm{~Hz}$. Our dataset could help establishing a basis to differentiate types of clay at lower frequencies $(<1000 \mathrm{~Hz})$ using the widely used low frequency geo-electrical methods. We understand that, just because we can see a clear difference in the resistivity values of our clay samples (see Table 5), this does not necessarily mean that, this differentiation could be done for all field conditions. Differentiating types of clay would depend on the clay samples themselves and the resolution of method used for the data collection in the field. As future work, we could use our dataset as a basis for forward-modeling to better understand if the differentiation of types of clay would be possible at the field scale. Also more experiments at a larger laboratory scale (pluri-decimetric) to test if we are able to differentiate types of clay using geo-electrical methods in a controlled environment.

\section{Conclusions}

We present a new laboratory protocol to characterize clay samples with good repeatability, and a new SIP dataset consisting of four different types of clay (red and green montmorillonite samples, an illite sample, and a kaolinite sample) at five different $\mathrm{NaCl}$ salinities (from initially de-ionized water to $1 \mathrm{M} \mathrm{NaCl}$ ). Our data shows an increase of the real part of the conductivity with salinity, while there is a non-monotonous behavior with the imaginary conductivity. A possible interpretation of this behavior could be that as salinity increases, coagulation happens. At a particular salinity threshold some 
polarization mechanisms cease to act, possibly membrane polarization effects, thus decreasing at a particular salinity the imaginary conductivity of the clay sample. There is a difference in the peak of polarization between clay types, varying both with salinity and in amplitude. Montmorillonite samples may present this polarizability peak at a higher salinity than the kaolinite and illite samples. This agrees with the fact that smectites need a higher ion concentration in the pore water to diminish membrane polarization effects and favour particle coagulation. We calculate the surface conductivities of the clay samples for the four highest salinities and we confirm that both montmorillonite samples have higher surface conductivities with respect to the kaolinite and illite samples and correlate well with the measured CEC. We found the linear parameter $(l)$ between both surface conductivities to be 0.0039 for our dataset. A wider dataset of clayey materials would seem to suggest that $l$ decreases with clay content.

More work on the side of the physical modeling needs to be done in order to be able to interpret our dataset by polarization mechanisms. Additionally more laboratory work, at a slightly bigger scale (pluri-decimetric) or directly field scale using multi-frequency geo-electrical methods could be used to validate the differentiation of clay types at bigger scales.

\section{Acknowledgments}

The authors strongly thank the financial support of ANR EXCITING (grant ANR-17CE06-0012) for this work and for the PhD thesis funding of A. Mendieta. We would also like to thank: Claude Fontaine, Philippe Cosenza, Céline Boissard, and Patricia Patrier. Members of the HydrASA team of the University of Poitiers for performing the XRD and CEC measurements on the different types of clay samples. We thank the associate editor, Niklas Linde, Lee Slater and two anonymous reviewers for their insightful comments that allowed us to improve our manuscript immensely. The data used in this study will be available on a zenodo repository (doi:10.5281/zenodo.4050345) after acceptance of the paper.

\section{References}

Auken, E., Boesen, T., \& Christiansen, A. V. (2017). A Review of Airborne Electromagnetic Methods With Focus on Geotechnical and Hydrological Applications From 2007 to 2017. In Advances in geophysics (Vol. 58, pp. 47-93). Elsevier Inc. 
doi: 10.1016/bs.agph.2017.10.002

Batayneh, A. T. (2006). Resistivity tomography as an aid to planning gas-pipeline construction, Risha area, north-east Jordan. Near Surface Geophysics, 4, 313-319. doi: $10.3997 / 1873-0604.2005053$

Bergaya, F., \& Lagaly, G. (2006). General introduction: clays, clay minerals, and clay science. $\quad$ In B. F., T. B.K.G., \& L. G. (Eds.), Handbook of clay science (1st ed., Vol. 1, pp. 1-18). Elsevier Ltd. doi: 10.1016/S1572-4352(05)01001-9

Börner, F. (1992). Complex conductivity measurements of reservoir properties. In P. Worthington \& C. Chardaire-Rivière (Eds.), Advances in core evaluation: Reservoir management: Reviewed proceedings of the society for core analysis third european core analysis symposium (pp. 359-386). Hardwood Academic.

Bourg, I. C., \& Sposito, G. (2011). Molecular dynamics simulations of the electrical double layer on smectite surfaces contacting concentrated mixed electrolyte (NaCl-CaCl2) solutions. Journal of Colloid And Interface Science, 360(2), 701715. Retrieved from http://dx.doi.org/10.1016/j.jcis.2011.04.063 doi: 10.1016/j.jcis.2011.04.063

Breede, K., Kemna, A., Esser, O., Zimmermann, E., Vereecken, H., \& Huisman, J. A. (2012). Spectral induced polarization measurements on variably saturated sand-clay mixtures. $\quad$ Near Surface Geophysics, 10, 479-489. doi: $10.3997 / 1873-0604.2012048$

Brigatti, M. F., Galan, E., \& Theng, B. K. (2006). Structures and Mineralogy of Clay Minerals. $\quad$ In B. F., T. B.K.G., \& L. G. (Eds.), Handbook of clay science (Vol. 1, pp. 19-86). Elsevier Ltd. doi: 10.1016/S1572-4352(05)01002-0

Brindley, G., \& Brown, G. (1980). C Crystal structures of Clay Minerals and Their X-ray Identification. Mineralogical Society Monograph No. 5. London: The Mineralogical Society of Great Britain and Ireland.

Bücker, M., Flores Orozco, A., Undorf, S., \& Kemna, A. (2019). On the Role of Stern- and Diffuse-Layer Polarization Mechanisms in Porous Media. Journal of Geophysical Research: Solid Earth, 124, 5656-5677. doi: 10.1029/2019JB017679

Bücker, M., \& Hördt, A. (2013). Analytical modelling of membrane polarization with explicit parametrization of pore radii and the electrical double layer. Geophysical Journal International, 194, 804-813. doi: 10.1093/gji/ggt136

Caceci, M., \& Cacheris, W. (1984). Fitting curves to data. The Simplex algorithm is 
the answer. Byte, 9, 340-362.

Chen, Y., \& Or, D. (2006). Effects of Maxwell-Wagner polarization on soil complex dielectric permittivity under variable temperature and electrical conductivity. $W a-$ ter Resources Research, 42, 1-14. doi: 10.1029/2005WR004590

Chorover, J., Kretzschmar, R., Garica-Pichel, F., \& Sparks, D. L. (2007). Soil biogeochemicial processes within the critical zone. Elements, 3, 321-326. doi: 10 .2113 /gselements.3.5.321

Chung, F. H. (1974). Quantitative interpretation of X-ray diffraction patterns of mixtures. I. Matrix-flushing method for quantitative multicomponent analysis. Journal of Applied Crystallography, 7, 519-525. doi: 10.1107/s0021889874010375

Ciesielski, H., \& Sterckeman, T. (1997). Determination of cation exchange capacity and exchangeable cations in soils by means of cobalt hexamine trichloride. Effects of experimental conditions. Agronomie, 17, 1-7. doi: 10.1051/agro:19970101

Cole, K. S., \& Cole, R. H. (1941). Dispersion and Absorption in Dielectrics. Journal of Chemical Physics, 9, 341. doi: https://doi.org/10.1063/1.1750906

Corrado, S., Aldega, L., Celano, A. S., De Benedetti, A. A., \& Giordano, G. (2014). Cap rock efficiency and fluid circulation of natural hydrothermal systems by means of XRD on clay minerals (Sutri, Northern Latium, Italy). Geothermics, 50, 180-188. doi: 10.1016/j.geothermics.2013.09.011

Cosenza, P., Ghorbani, A., Revil, A., Zamora, M., Schmutz, M., Jougnot, D., \& Florsch, N. (2008). A physical model of the low-frequency electrical polarization of clay rocks. Journal of Geophysical Research, 113, 1-9. doi: 10.1029/2007JB005539

de Lima, O. A., \& Sharma, M. M. (1990). A grain conductivity approach to shaly sandstones. Geophysics, 55, 1347-1356. doi: doi:https://doi.org/10.1190/ 1.1442782

Finco, C., Pontoreau, C., Schamper, C., Massuel, S., Hovhannissian, G., \& Rejiba, F. (2018). Time-domain electromagnetic imaging of a clayey confining bed in a brackish environment: A case study in the Kairouan Plain Aquifer (Kelbia salt lake, Tunisia). Hydrological Processes, 32, 3954-3965. doi: 10.1002/hyp.13303

Garrels, R. M., \& Mackenzie, F. (1971). Evolution of sedimentary rocks. New York.

Ghorbani, A., Cosenza, P., Revil, A., Zamora, M., Schmutz, M., Florsch, N., \& Jougnot, D. (2009). Non-invasive monitoring of water content and textural 
changes in clay-rocks using spectral induced polarization: A laboratory investigation. Applied Clay Science, 43, 493-502. doi: 10.1016/j.clay.2008.12.007

Gonçalvès, J., de Marsily, G., \& Tremosa, J. (2012). Importance of thermoosmosis for fluid flow and transport in clay formations hosting a nuclear waste repository. $\quad$ Earth and Planetary Science Letters, 339-340, 1-10. doi: 10.1016/j.epsl.2012.03.032

Hassan, M. S., Villieras, F., Gaboriaud, F., \& Razafitianamaharavo, A. (2006) AFM and low-pressure argon adsorption analysis of geometrical properties of phyllosilicates. Journal of Colloid and Interface Science, 296, 614-623. doi: $10.1016 /$ j.jcis.2005.09.028

Hillier, S. (2003). Quantitative Analysis of Clay and other Minerals in Sandstones by X-Ray Powder Diffraction (XRPD). Int. Assoc. Sedimentol. Spec. Publ., 34, 213251. doi: $10.1002 / 9781444304336 . \operatorname{ch} 11$

Hördt, A., Bairlein, K., Bielefeld, A., Bücker, M., Kuhn, E., Nordsiek, S., \& Stebner, H. (2016). The dependence of induced polarization on fl uid salinity and $\mathrm{pH}$, studied with an extended model of membrane polarization. Journal of Applied Geophysics, 135, 408-417. doi: 10.1016/j.jappgeo.2016.02.007

Huisman, J. A., Zimmermann, E., Esser, O., Haegel, F. H., Treichel, A., \&

Vereecken, H. (2016). Evaluation of a novel correction procedure to remove electrode impedance effects from broadband SIP measurements. Journal of Applied Geophysics, 135, 466-473. doi: 10.1016/j.jappgeo.2015.11.008

Islam, M., Chittoori, B., \& Burbank, M. (2020). Evaluating the Applicability of Biostimulated Calcium Carbonate Precipitation to Stabilize Clayey Soils. Journal of Materials in Civil Engineering, 32, 1-11. doi: 10.1061/(ASCE)MT.1943-5533 .0003036

Jougnot, D., Ghorbani, A., Revil, A., Leroy, P., \& Cosenza, P. (2010). Spectral induced polarization of partially saturated clay-rocks : a mechanistic approach. Geophysical Journal International, 180, 210-224. doi: 10.1111/j.1365-246X.2009.04426 . $\mathrm{X}$

Kemna, A., Binley, A., Cassiani, G., Niederleithinger, E., Revil, A., Slater, L., ... Zimmermann, E. (2012). An overview of the spectral induced polarization method for near-surface applications. $\quad$ Near Surface Geophysics, 10, 453-468. doi: $10.3997 / 1873-0604.2012027$ 
Khaled, E. M., \& Stucki, J. W. (1991). Iron Oxidation State Effects on Cation Fixation in Smectites. Soil Science Society of America Journal1, 55(2), 550-554.

Konikow, L., August, L., \& Voss, C. (2001). Effects of clay dispersion on aquifer storage and recovery in coastal aquifers. $\quad$ Transport in Porous Media, 43, 45-64. doi: $10.1023 / \mathrm{A}: 1010613525547$

Kremer, T., Schmutz, M., Maineult, A., \& Agrinier, P. (2016). Laboratory monitoring of $\mathrm{CO} 2$ injection in saturated silica and carbonate sands using spectral induced polarization. Geophysical Journal International, 207, 1258-1272. doi: $10.1093 /$ gji /ggw333

Leroy, P., Li, S., Jougnot, D., Revil, A., \& Wu, Y. (2017b). Modelling the evolution of complex conductivity during calcite precipitation on glass beads. Geophysical Journal International, 209, 123-140. doi: 10.1093/gji/ggx001

Leroy, P., \& Revil, A. (2004). A triple-layer model of the surface electrochemical properties of clay minerals. Journal of Colloid and Interface Science, 270, 371380. doi: $10.1016 /$ j.jcis.2003.08.007

Leroy, P., \& Revil, A. (2009). A mechanistic model for the spectral induced polarization of clay materials. Journal of Geophysical Research, 114(B10202), 1-21. doi: 10.1029/2008JB006114

Leroy, P., Tournassat, C., Bernard, O., Devau, N., \& Azaroual, M. (2015). The electrophoretic mobility of montmorillonite. Zeta potential and surface conductivity effects. Journal of Colloid And Interface Science, 451, 21-39. doi: 10.1016/j.jcis.2015.03.047

Leroy, P., Weigand, M., Mériguet, G., Zimmermann, E., Tournassat, C., Fagerlund, F., .. Huisman, J. A. (2017a). Spectral induced polarization of Namontmorillonite dispersions. Journal of Colloid And Interface Science, 505, 1093-1110. doi: 10.1016/j.jcis.2017.06.071

Lesmes, D. P., \& Frye, K. M. (2001). Influence of pore fluid chemistry on the complex conductivity and induced polarization responses of Berea sandstone. Journal of Geophysical Research: Solid Earth(B3), 4079-4090. doi: 10.1029/2000jb900392

Lévy, L., Gibert, B., Sigmundsson, F., Flóvenz, O. G., Hersir, G. P., Briole, P., \& Pezard, P. A. (2018). The role of smectites in the electrical conductivity of active hydrothermal systems: Electrical properties of core samples from Krafla volcano, Iceland. Geophysical Journal International, 215, 1558-1582. doi: 
$10.1093 /$ gji /ggy342

Lévy, L., Maurya, P. K., Byrdina, S., Vandemeulebrouck, J., Sigmundsson, F., Árnason, K., ... Labazuy, P. (2019a). Electrical resistivity tomography and time-domain induced polarization field investigations of geothermal areas at Krafla, Iceland: Comparison to borehole and laboratory frequency-domain electrical observations. Geophysical Journal International, 218, 1469-1489. doi: $10.1093 / \mathrm{gji} / \mathrm{ggz} 240$

Lévy, L., Weller, A., \& Gibert, B. (2019b). Influence of smectite and salinity on the imaginary and surface conductivity of volcanic rocks. Near Surface Geophysics, 17, 653-673. doi: 10.1002/nsg.12069

Looms, M. C., Klotzsche, A., van der Kruk, J., Larsen, T. H., Edsen, A., Tuxen, N., .. Nielsen, L. (2018). Mapping sand layers in clayey till using crosshole groundpenetrating radar. Geophysics, 83, A21-A26. doi: 10.1190/GEO2017-0297.1

Ma, C., \& Eggleton, R. (1999). Cation Exchange Capacity of Kaolinite. Clays and Clay Minerals, 47, 174-180. doi: https://doi.org/10.1346/CCMN.1999.0470207

Maineult, A. (2016). Estimation of the electrical potential distribution along metallic casing from surface self-potential profile. Journal of Applied Geophysics, 129, 66-78. doi: 10.1016/j.jappgeo.2016.03.038

Maineult, A., Revil, A., Camerlynck, C., Florsch, N., \& Titov, K. (2017). Upscaling of spectral induced polarization response using random tube networks. Geophysical Journal International, 209, 948-960. doi: 10.1093/gji/ggx066

Meier, L. P., \& Kahr, G. (1999). Determination of the Cation Exchange Capacity (CEC) of Clay Minerals Using the Complexes of Copper(II) Ion with Triethylenetetramine and Tetraethylenepentamine. Clays and Clay Minerals, 47(3), 386-388. doi: 10.1346/ccmn.1999.0470315

Michot, L. J., \& Villiéras, F. (2006). Surface Area and Porosity. In F. Bergaya, B. K. Theng, \& G. Lagaly (Eds.), Handbook of clay science (Vol. 1, pp. 965-978). Elsevier Ltd. doi: 10.1016/S1572-4352(05)01035-4

Mitchell, J. K., \& Soga, K. (2005). Fundamentals of Soil Behavior (3rd ed.). John Wiley \& Sons. doi: 10.1097/00010694-199407000-00009

Moore, D., \& Reynolds, R. (1989). X-ray diffraction and the identification and analysis of clay minerals. Oxford University Press.

Morsy, S., \& Sheng, J. (2014). Effect of Water Salinity on Shale Reservoir Produc- 
tivity. Advances in Petroleum Exploration and Development, 8, 9-14. doi: 10 $.3968 / 5604$

Okay, G., Cosenza, P., Ghorbani, A., Camerlynck, C., Cabrera, J., Florsch, N., \& Revil, A. (2013). Localization and characterization of cracks in clay-rocks using frequency and time-domain induced polarization. Geophysical Prospecting, 61, 134-152. doi: 10.1111/j.1365-2478.2012.01054.x

Okay, G., Leroy, P., Ghorbani, A., Cosenza, P., Camerlynck, C., Cabrera, J., .. Revil, A. (2014). Spectral induced polarization of clay-sand mixtures : Experiments and modeling. Geophysics, 79, 353-375. doi: 10.1190/GEO2013-0347.1

Ortiz, L., Volckaert, G., \& Mallants, D. (2002). Gas generation and migration in Boom Clay, a potential host rock formation for nuclear waste storage. Engineering Geology, 64, 287-296. doi: 10.1016/S0013-7952(01)00107-7

Parker, B. L., Chapman, S. W., \& Guilbeault, M. A. (2008). Plume persistence caused by back diffusion from thin clay layers in a sand aquifer following TCE source-zone hydraulic isolation. Journal of Contaminant Hydrology, 102, 86-104. doi: $10.1016 /$ j.jconhyd.2008.07.003

Pelton, W., Ward, S. H., Hallof, P. G., Sill, W. R., \& Nelson, P. H. (1978). Mineral discrimination and removal of inductive coupling with multifrequency IP. Geophyics, 43, 588-609. doi: https://doi.org/10.1190/1.1440839

Revil, A. (2012). Spectral induced polarization of shaly sands: Influence of the electrical double layer. Water Resources Research, 48(2), 1-23. doi: 10.1029/ 2011WR011260

Revil, A., Florsch, N., \& Camerlynck, C. (2014). Spectral induced polarization porosimetry. Geophysical Journal International, 198, 1016-1033. doi: 10.1093/gji/ ggu180

Revil, A., Karaoulis, M., Johnson, T., \& Kemna, A. (2012). Review : Some lowfrequency electrical methods for subsurface characterization and monitoring in hydrogeology. Hydrogeology Journal, 20, 617-658. doi: 10.1007/s10040-011-0819-x

Revil, A., \& Leroy, P. (2004). Constitutive equations for ionic transport in porous shales. Journal of Geophysical Research, 109, 1-19. doi: 10.1029/2003jb002755

Revil, A., \& Skold, M. (2011). Salinity dependence of spectral induced polarization in sands and sandstones. Geophysical Journal International, 187, 813-824. doi: 10 $.1111 / \mathrm{j} .1365-246 \mathrm{X} .2011 .05181 . \mathrm{x}$ 
Schwartz, N., \& Furman, A. (2015). On the spectral induced polarization signature of soil organic matter. Geophysical Journal International, 200, 589-595. doi: 10 $.1093 / \mathrm{gji} / \mathrm{ggu} 410$

Schwarz, G. (1962). A theory of the low-frequency dielectric dispersion of colloidal particles in electrolyte solution. Journal of Physical Chemistry, 66, 2636-2642. doi: $10.1021 / \mathrm{j} 100818 \mathrm{a} 067$

Sondi, I., Biscan, J., \& Pravdic, V. (1996). Electrokinetics of Pure Clay Minerals Revisited. Journal of Colloid And Interface Science, 178, 514-522. doi: https:// doi.org $/ 10.1006 /$ jcis. 1996.0403

Spichak, V., \& Manzella, A. (2009). Electromagnetic sounding of geothermal zones. Journal of Applied Geophysics, 68, 459-478. doi: 10.1016/j.jappgeo.2008.05.007

Tabbagh, A., Rejiba, F., Finco, C., Schamper, C., Souffaché, B., Camerlynck, C., ... Maineult, A. (2021). The Case for Considering Polarization in the Interpretation of Electrical and Electromagnetic Measurements in the $3 \mathrm{kHz}$ to $3 \mathrm{MHz}$ Frequency Range. Surveys in Geophysics. doi: 10.1007/s10712-020-09625-1

Tombácz, E., \& Szekeres, M. (2006). Surface charge heterogeneity of kaolinite in aqueous suspension in comparison with montmorillonite. Applied Clay Science, 34, 105-124. doi: 10.1016/j.clay.2006.05.009

Tournassat, C., Bizi, M., Braibant, G., \& Crouzet, C. (2011). Influence of montmorillonite tactoid size on Na-Ca cation exchange reactions. Journal of Colloid and Interface Science, 364, 443-454. doi: 10.1016/j.jcis.2011.07.039

Tournassat, C., Bourg, I. C., Steefel, C. I., \& Bergaya, F. (2015). Surface Properties of Clay Minerals. In C. Tournassat, C. I. Steefel, I. C. Bourg, \& F. Bergaya (Eds.), Developments in clay science (Vol. 6, pp. 5-31). Elsevier. doi: 10.1016/ B978-0-08-100027-4.00001-2

Tournassat, C., Grangeon, S., Leroy, P., \& Giffaut, E. (2013). Modeling specific pH dependent sorption of divalent metals on montmorillonite surfaces. A review of pitfalls, recent achievements and current challenges. American Journal of Science, 313, 395-451.

Tournassat, C., Neaman, A., Villéras, F., Bosbach, D., \& Charlet, L. Nanomorphology of montmorillonite particles: Estimation of the clay edge sorption site density by low-pressure gas adsorption and AFM observations. American Mineralogist, 88, 1989-1995. doi: 10.2138/am-2003-11-1243 
Tournassat, C., \& Steefel, C. I. (2015). Ionic transport in nano-porous clays with consideration of electrostatic effects. Reviews in Mineralogy $\mathcal{G}$ Geochemistry, 80, 287-329. doi: http://dx.doi.org/10.2138/rmg.2015.80.09

Tournassat, C., \& Steefel, C. I. (2019). Reactive Transport Modeling of Coupled Processes in Nanoporous Media. Reviews in Mineralogy and Geochemistry, 85, 75-109. doi: $10.2138 / \mathrm{rmg} .2019 .85 .4$

Tsujimoto, Y., Chassagne, C., \& Adachi, Y. (2013). Dielectric and electrophoretic response of montmorillonite particles as function of ionic strength. Journal of Colloid and Interface Science, 404, 72-79. doi: 10.1016/j.jcis.2013.03.033

Vinegar, H. J., \& Waxman, M. H. (1984). Induced Polarization of Shaly Sands - the Effect of Clay Counterion Type. Log Analyst, 25, 11-21.

Wagner, J. F. (2013). Mechanical properties of clays and clay minerals. In F. Bergaya \& G. Lagaly (Eds.), Handbook of clay science (2nd ed., Vol. 5A, pp. 347-381). Elsevier Inc. doi: 10.1016/B978-0-08-098258-8.00011-0

Wang, C., \& Slater, L. D. (2019). Extending accurate spectral induced polarization measurements into the $\mathrm{kHz}$ range: Modelling and removal of errors from interactions between the parasitic capacitive coupling and the sample holder. Geophysical Journal International, 218, 895-912. doi: 10.1093/gji/ggz199

Waxman, M. H., \& Smits, L. J. (1968). Electrical Conductivities in Oil-Bearing Shaly Sands. Society of Petroleum Engineers Journal, 243, 107-122. doi: 10.2118/ $1863-\mathrm{A}$

Weller, A., \& Slater, L. (2012). Salinity dependence of complex conductivity of unconsolidated and consolidated materials: Comparisons with electrical double layer models. Geophysics, 77, D185-D198. doi: 10.1190/geo2012-0030.1

Weller, A., Slater, L., Huisman, J. A., Esser, O., \& Haegel, F. H. (2015a). On the specific polarizability of sands and sand-clay mixtures. Geophysics, 80, A57-A61. doi: 10.1190/GEO2014-0509.1

Weller, A., Slater, L., \& Nordsiek, S. (2013). On the relationship between induced polarization and surface conductivity: Implications for petrophysical interpretation of electrical measurements. Geophysics, 78, D315-D325. doi: 10.1190/GEO2013-0076.1

Weller, A., Slater, L., Nordsiek, S., \& Ntarlagiannis, D. (2010). On the estimation of specific surface per unit pore volume from induced polarization: A robust 
empirical relation fits multiple data sets. Geophysics, 75, WA105-WA112. doi: $10.1190 / 1.3471577$

Weller, A., Zhang, Z., \& Slater, L. (2015b). High-salinity polarization of sandstones. Geophysics(3), D309-D318. doi: 10.1190/GEO2014-0483.1

White, W. A. (1949). Atterberg plastic limits of clay minerals. American Mineralogist, 34, 508-512. doi: https://doi.org/

Woodruff, W. F., Revil, A., \& Torres-Verdín, C. (2014). Laboratory determination of the complex conductivity tensor of unconventional anisotropic shales. Geophysics, 79, E183-E200. doi: 10.1190/GEO2013-0367.1

Zanetti, C., Weller, A., Vennetier, M., \& Mériaux, P. (2011). Detection of buried tree root samples by using geoelectrical measurements: A laboratory experiment. Plant Soil, 339, 273-283. doi: 10.1007/s11104-010-0574-0

Zimmermann, E., Kemna, A., Berwix, J., Glaas, W., Münch, H. M., \& Huisman, J. A. (2008). A high-accuracy impedance spectrometer for measuring sediments with low polarizability. Measurement Science and Technology, 19, 1-9. doi: $10.1088 / 0957-0233 / 19 / 10 / 105603$

Zonge, K., Wynn, J., \& Urquhart, S. (2005). Resistivity, induced polarization, and complex resistivity. In D. K. Butler (Ed.), Near surface geophysics (pp. 265-300). Society of Exploration Geophysicists. doi: https://doi.org/10.1190/ 1.9781560801719.ch9 